\title{
A PSYCHOPHYSIOLOGICAL ASSESSMENT OF DELAYED EMOTIONAL RECOVERY ACROSS DISCRETE EMOTIONS IN BORDERLINE PERSONALITY DISORDER AND THE IMPACT OF SELF-HARM AND SUICIDALITY
}

by

\author{
Skye Fitzpatrick B.A., \\ Dalhousie University, 2011 \\ A thesis presented to Ryerson University+ \\ in partial fulfillment of the requirements for the degree of Master of Arts in the Program of \\ Psychology \\ Toronto, Ontario, Canada, 2013 \\ (C)Skye Fitzpatrick, 2013
}




\section{AUTHOR'S DECLARATION FOR ELECTRONIC SUBMISSION OF A THESIS}

I hereby declare that I am the sole author of this thesis. This is a true copy of the thesis, including any required final revisions, as accepted by my examiners.

I authorize Ryerson University to lend this thesis to other institutions or individuals for the purpose of scholarly research.

I further authorize Ryerson University to reproduce this thesis by photocopying or by other means, in total or in part, at the request of other institutions or individuals for the purpose of scholarly research. I understand that my thesis may be made electronically available to the public. 
A Psychophysiological Assessment of Delayed Emotional Recovery Across Discrete Emotions in Borderline Personality Disorder and the Impact of Self-Harm and Suicidality

Skye Fitzpatrick

Psychology, Ryerson University

Master of Arts

Toronto, ON, 2013

Abstract
This study examined Linehan's (1993) theory of delayed emotional recovery (i.e., emotions last longer) in borderline personality disorder (i.e., BPD), and whether non-suicidal self-injury and suicidal ideation modulate this process. BPD and healthy control (HC) groups were monitored via parasympathetic, sympathetic, and self-report indices after fear, anger, and sadness inductions. After the fear induction, the BPD group showed increases in emotional arousal as indicated by parasympathetic indices and no changes in sympathetic indices, whereas HCs showed no change in parasympathetic indices and decreases in sympathetic indices. Further, individuals with BPD with higher urges to commit suicide after the fear induction exhibited faster decreases in sympathetic responding than others. These findings suggest that individuals with BPD selectively show delayed emotional recovery and that suicidal ideation may quicken emotional recovery in this group. Those with BPD may benefit from learning strategies to quicken, or tolerate, delayed emotional recovery. 


\section{Acknowledgements}

To engage in behaviour as daunting as thesis writing requires pretty compelling contingencies. Fortunately for me, I am surrounded by reinforcers both in human and snack form.

First, I wish to express gratitude to the members of my supervisory and defense committees, Dr. Candice Monson and Dr. Karen Milligan. Their insight and dedication of their time is beyond collegial and generous. Dr. Monson's ongoing thoughtful feedback throughout the entire thesis process from the proposal forward significantly strengthened this work.

Second, I owe my supervisor, Dr. Janice Kuo, immense gratitude. Working under Dr. Kuo's supervision is inherently reinforcing, and this thesis exists due to her continual support and mentorship. I hope that observational learning applies to academia, because Dr. Kuo is unwavering in modeling an ineffable kind of intellectual courage. I will be very fortunate if even a small degree of her rigorous and thoughtful approach to research, mentorship, and clinical practice makes its way into my repertoire.

I would like to thank my family and friends for their support and guidance throughout the process. My parents have been incredibly generous and supportive with both their love and their food and I am truly fortunate to be have had their support throughout this process. I would also like to thank my partner for, among other things, always bringing me snacks and overwhelming amounts of tea so that I could keep writing this thesis. You're the very best.

I would also like to thank the members of the Borderline Personality Disorder and Emotion Processing Laboratory (BEP Lab), and in particular my colleague Rebecca Metcalfe, for their support and feedback. Finally, I am very grateful to the women who participated in this research. Their contribution is invaluable. 
Table of Contents

CHAPTER I: Introduction

Delayed Emotional Recovery in BPD

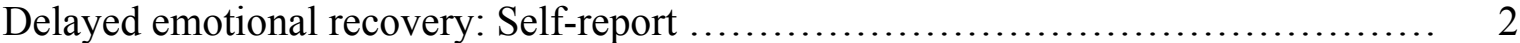

Delayed emotional recovery: Psychophysiology ................................ 4

Physiological assessment of emotion: Parasympathetic and sympathetic emotional

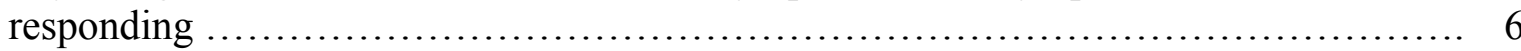

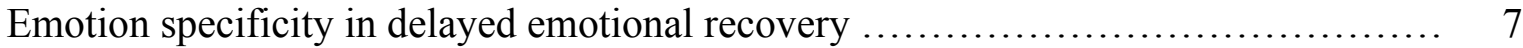

BPD-relevant confounds .................................................... 8

Difficulties with Emotion Regulation in BPD .................................... 9

NSSI, Suicidal Ideation, and Delayed Emotional Recovery $\ldots \ldots \ldots \ldots \ldots \ldots \ldots \ldots \ldots . . \ldots$

Hypotheses.............................................................. 12

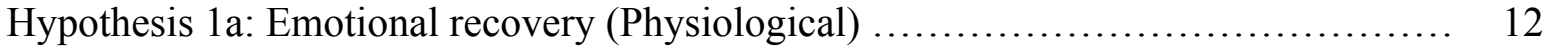

Hypothesis 1b: Emotional recovery (Self-Report) ............................ 12

Hypothesis 2a: Emotion regulation strategies (Self-Report) .................... 12

Hypothesis 2b: Emotional recovery and emotion regulation strategies (Physiological) 13

Hypothesis 2c: Emotional recovery and emotion regulation strategies (Self-Report) ... 13

CHAPTER II: Method

Participants................................................................... 13

Power analyses......................................................... 15

Measures...................................................................... 15

Screening and descriptive measures........................................ 15

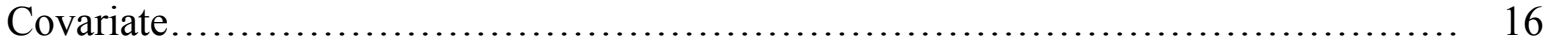

Emotion regulation strategy measures ........................................ 17

Self-reported arousal .................................................... 17

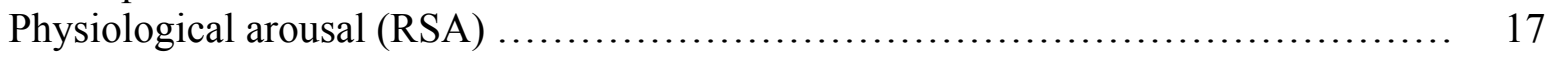

Physiological arousal (SCR) ............................................. 17

Emotion induction films .................................................... 18

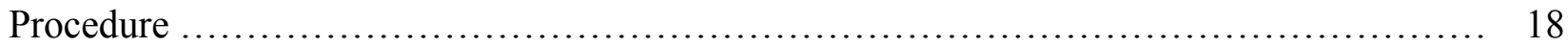

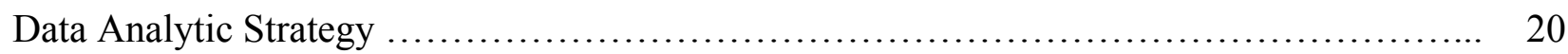

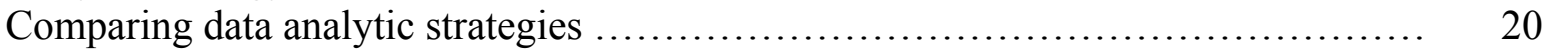

Covariates .............................................................. 22

Hypothesis 1b and 2c: Self-report data .................................... 23

CHAPTER III: Results

Missing Data................................................................ 25

Descriptive Statistics ...................................................... 25

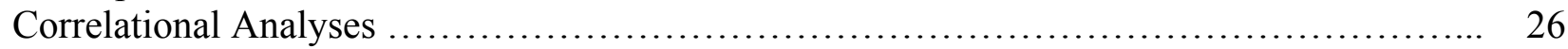

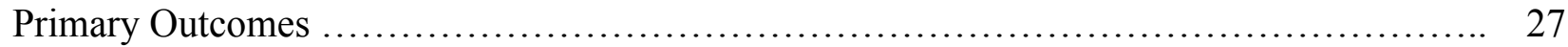

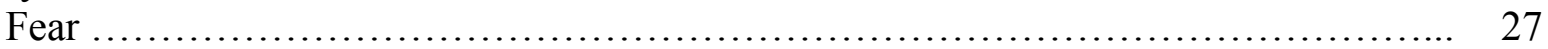

Self-Report Data ................................................. 28

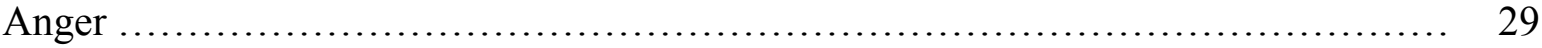

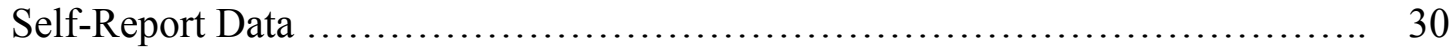

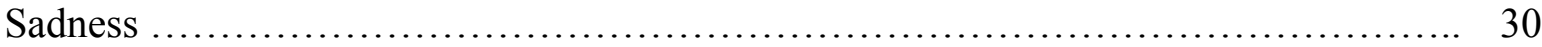

Self-Report Data ................................................. 31

CHAPTER IV: Discussion

Delayed Emotional Recovery and BPD 


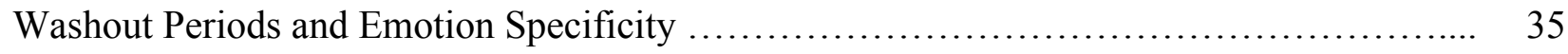

Psychophysiological and Self-Report Discrepancies ............................... 37

The Present Study in the Context of the Extant Literature ............................. 38

The Modulating Impact of Emotion Regulation Strategies on Delayed Emotional Recovery .. 38

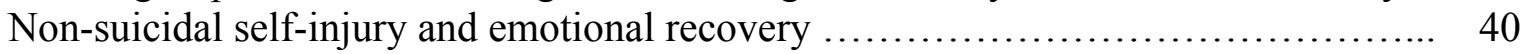

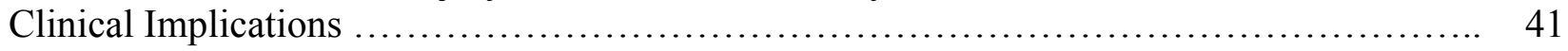

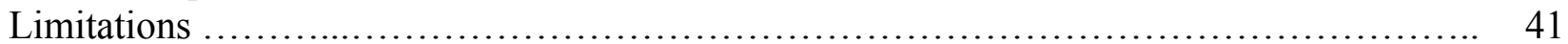

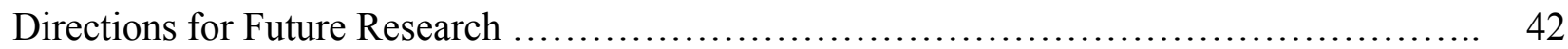

CHAPTER V: References $\quad 45$ 
List of Tables

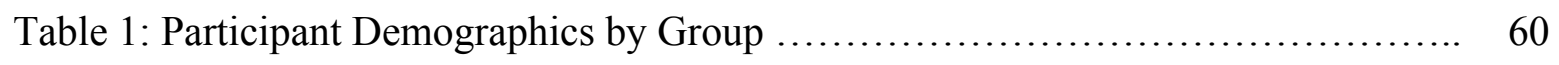

Table 2: Diagnostic Co-Morbidities in Percentages within the Borderline Personality

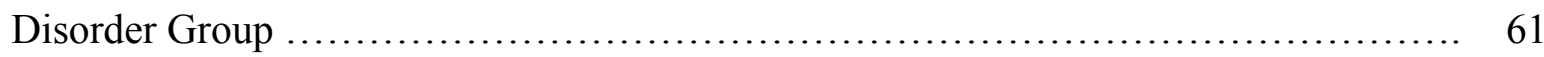

Table 3: Means, Standard Deviations, and Medians for Self-Reported Fear, Anger, and

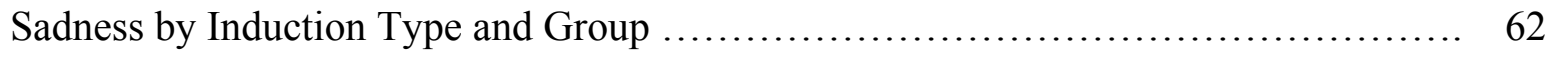

Table 4: Means and Standard Deviations for Psychophysiological Data Across

Experiment Periods by Induction Type and Group $\ldots \ldots \ldots \ldots \ldots \ldots \ldots \ldots \ldots \ldots \ldots \ldots \ldots$

Table 5: Hierarchical Linear Modeling Fixed Effects by Induction Type 64

Table 6: Indications of Multicollinearity Between Predictors and Interaction Terms in

Regression Analyses ................................................. 66

Table 7: Hierarchical Multiple Linear Regression Analyses of Self-Reported Changes

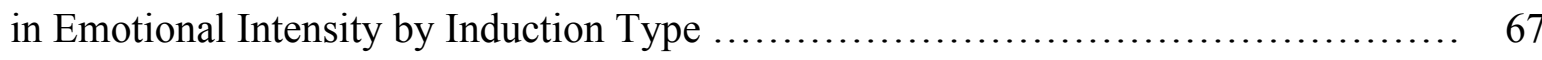




\section{List of Figures}

Figure 1: Schematic illustration of a sample participant's experimental trial. Selfreport measures used in the present study are bolded. Film presentation order was counterbalanced across participants ...............................

Figure 2: Group $\mathrm{X}$ time interaction in the fear condition predicting changes in respiratory sinus arrhythmia

Figure 3: Group $\mathrm{X}$ time interaction in the fear condition predicting changes in skin conductance responses

Figure 4: Changes in skin conductance responses over time grouped by high and low urges to commit suicide in the borderline personality disorder group only. High and low urges to commit suicide were delineated by a median split...... 
A Psychophysiological Assessment of Delayed Emotional Recovery Across Discrete Emotions in Borderline Personality Disorder and the Impact of Self-Harm and Suicidality Borderline personality disorder (BPD) is a disorder of impulsivity, self-destructive behaviour, and instability in self-image, interpersonal relationships, emotions, behaviour, and cognitions (APA, 2000). BPD is a serious public health concern, as $84 \%$ of individuals with BPD exhibit suicidal behaviour (Soloff, Lynch \& Kelly, 2002) and 10\% of individuals with BPD commit suicide (Paris \& Zweig-Frank, 2001). BPD is also highly co-morbid with other psychological disorders such as eating, substance use, mood, and anxiety disorders (Zanarini, Frankenburg, Dubo, Sickel, Trikha, Levin, \& Reynolds, 1998), and BPD features predict several maladaptive outcomes over time (e.g., social maladjustment; Bagge, Nickell, Stepp, Durrett, Jackson, \& Trull, 2004). Thus, there is a clear need to understand the psychological processes underpinning BPD and the ways in which they relate to each other in order to refine effective treatments.

Linehan (1993) posits that emotion dysregulation is the core feature of BPD, such that all BPD-relevant behaviours are either direct products of emotion dysregulation or maladaptive attempts to regulate emotions. According to this theory, emotion dysregulation involves heightened sensitivity (i.e., lower threshold for emotional reactions), heightened reactivity (i.e., greater changes from baseline in emotional intensity), and delayed emotional recovery (i.e., emotions last longer), coupled with difficulties with emotion regulation (i.e., lack or difficulty with either automatic or controlled efforts to alter emotion dynamics; Gross \& Thompson, 2007). A wealth of research has investigated whether individuals with BPD display heightened sensitivity (e.g., Baskin-Sommers, Vitale, MacCoon, \& Newman, 2012; Domes, Grabe, Czieschnek, Heinrichs, \& Herpertz, 2011; Jovev et al., 2011; Lynch et al., 2006; Tragesser, 
Lipman, Tull, \& Barrett, 2008), reactivity (e.g., Austin, Riniolo, \& Porges, 2007; Glaser, Van Os, Mengelers, \& Myin-Germeys, 2008; Gratz et al., 2010; Herpertz et al., 2000; Herpertz, Kunert, Schwenger, \& Sass, 1999; Kuo \& Linehan, 2009; Lobbestael \& Arntz, 2010; Marissen, Meuleman, \& Franken, 2010; Sadikaj, Russell, Moskowitz, \& Paris, 2010; Schmahl et al., 2004; Staebler, Gebhard, Barnett, \& Renneberg, 2009), and difficulties with emotion regulation (e.g., Barnow et al., 2012; Chapman, Dixon-Gordon, \& Walters, 2011; Cheavens, Strunk, \& Chriki, 2012; Conklin, Bradley, \& Westen, 2006; Glenn \& Klonsky, 2009; Gratz et al., 2009; Iverson, Follette, Pistorello, \& Fruzzetti, 2012; Johnson, Hurley, Benklefat, \& Herpertz, 2003; Neidtfeld et al., 2010; Neidtfeld et al., 2012; Salsman \& Linehan, 2012). However, substantially less empirical attention has been devoted to examining whether individuals with BPD display a more delayed emotional recovery than others.

\section{Delayed Emotional Recovery in BPD}

Delayed emotional recovery: Self-report. Of the few studies that have examined delayed emotional recovery in BPD, the data are mixed. In the first study, individuals with BPD, individuals with major depressive disorder, and healthy controls (HCs) read an anger-inducing story and completed self-report measures of anger, joy, shame, anxiety, and sadness during, 3 minutes, and 6 minutes after the anger induction. There were no differences between groups in change over the time points, suggesting that individuals with BPD do not show a slower emotional recovery (Jacob et al., 2009).

Gratz, Rosenthal, Tull, Lejeuz, and Gunderson (2010) utilized a similar methodology and produced similar results. These authors exposed individuals with BPD and outpatients without a personality disorder to both a general and negative feedback stressor and examined both emotional reactivity and emotional recovery through changes in self-reported shame, anxiety, 
irritability, and hostility. Self-reported emotional intensity was assessed before the induction, three times during the stressors, and 5 minutes after the stressors. Emotional recovery was assessed using two different forms of statistical analysis. The first analysis examined whether the groups differed in changes in emotional intensity from before to after the stressors. Results showed that only the BPD group demonstrated significantly higher self-reported shame after the stressor relative to before the stressor, indicating that the BPD group failed to return to their prestressor emotional intensity levels post-stressor. Results also showed that the BPD group demonstrated larger changes in self-reported shame from before the stressor to during the stressor (reactivity). Consequently, the second analysis compared changes in individual's peak levels of emotional intensity during the stressor to their emotional intensity after the stressor. Importantly, the groups did not differ in the change between the peak-intensity of shame during the stressors to the level of shame after the stressor, suggesting that the BPD group did not show delayed emotional recovery. Therefore, though individuals with BPD appear to have higher emotional intensity after stressors compared to before stressors, this appears to be accounted for by larger changes in emotional intensity during the stressors (i.e., heightened reactivity). Thus, both studies did not support delayed emotional recovery and Gratz and colleagues' (2010) findings suggest that alternate emotional processes (i.e., reactivity) may account for what appears to be delayed emotional recovery in BPD.

Though the studies mentioned above provide an important contribution to the literature, some key issues limit the findings to date. First, the studies were solely based on self-report. Research indicates that subjective emotionality is merely one domain of a multifaceted emotional response with experiential, behavioural, and physiological components that do not necessarily correlate with each other (Gross \& Thompson, 2007). A more rigorous examination of delayed 
emotional recovery therefore requires examination of multiple indices of emotional responding (e.g., self-report, physiological).

Second, both studies examined rates of change between very few (e.g., two or three) data points (e.g., induction and post-induction). Assessment of delayed emotional recovery fundamentally involves examining change in emotional responding over time. Both of these studies were only able to assess rates of change according to the difference between two (Gratz et al., 2010) or three (Jacob et al., 2009) discrete data points that were separated by lengthy periods of time (e.g., 3 minutes; Jacob et al., 2009). It is possible that a more complex trajectory is missed when only change scores based such few data points are examined. A more informative and comprehensive examination of the rates of emotional recovery requires more frequent assessments of emotional arousal.

Delayed emotional recovery: psychophysiology. Three additional studies examining delayed emotional recovery in BPD have improved upon these limitations by including psychophysiological assessments. Weinberg, Klonsky, and Hajcak (2009) exposed community participants who screened positive on a self-report measure of BPD symptoms and HCs to a laboratory stressor and evaluated changes in emotionality for 5 minutes following the stressor. Respiratory sinus arrhythmia (RSA; a measure of parasympathetic responding) and cardiac sympathetic index (i.e., sympathetic measure based on heart rate variability; Toichi, Suigura, Murai, \& Sengoku, 1997) were collected. Similar to the self-report studies reviewed above, there were no group differences in emotional recovery. This study is an improvement from the other literature reviewed because of its addition of psychophysiological assessment. However, similar to the other studies, it only examined changes in these indices across two data points (i.e., 
stressor and after the stressor). Therefore, some of the aforementioned limitations to the literature remain.

Another study improved upon these shortcomings by examining changes in cortisol and salivary-alpha amylase (i.e., indicator of autonomic arousal) during a stressor and five times following a stressor at 10 minute intervals in individuals with BPD, a trait-matched $\mathrm{HC}$ group (i.e., HCs that showed comparable scores to the BPD group on negative affect and impulsivity), and a non-trait-matched HC group (Scott, Levy, \& Granger, 2012). These authors also examined changes in self-reported negative affect from immediately after the stressor to 40 minutes after the stressor. Regular monitoring of changes in cortisol and salivary alpha-amylase allowed for more reliable assessment of emotional recovery. Despite these methodological improvements, the results failed to provide support for delayed emotional recovery across any indices in BPD relative to the two control groups.

Finally, Hazlett and colleagues (2012) conducted a functional magnetic resonance imaging study with individuals with BPD, schizotypal personality disorder, and HCs. Participants were consecutively presented with alternating fixation crosses and negative, pleasant images, and neutral images followed by a 2 second period in which they rated the image's valence. Examination of the average change in arousal for 30 seconds after each image revealed that the BPD group showed slower decreases in blood-oxygen level dependent responses across all image types. Though Hazlett and colleagues (2012) interpret these findings as indicative of delayed emotional recovery, the interpretation is confounded by the positive, negative, and neutral images being presented during the periods in which emotional recovery was assessed. That is, emotional recovery was assessed while emotional stimuli were still being presented to 
participants. As emotional recovery may require a termination of emotional stimuli, it is unclear whether these findings assess emotional recovery per se or habituation to emotional stimuli.

Weinberg and colleagues' (2009), Scott and colleagues' (2012), and Hazlett and colleagues' (2012) addition of psychophysiological or neuroimaging assessment provided notable improvements to the delayed emotional recovery literature. Moreover, this research also highlights additional key considerations in examinations of delayed emotional recovery that could further strengthen the aforementioned studies. Namely, the importance of distinct parasympathetic and sympathetic assessment, emotion specificity, and BPD-relevant confounds.

\section{Physiological assessment of emotion: Parasympathetic and sympathetic emotional}

responding. The autonomic nervous system regulates a variety of responses that are linked to emotional arousal and emotion regulation, and is divided into parasympathetic and sympathetic branches. Porges' Polyvagal Theory (Porges, Doussad-Roosevelt, \& Maiti, 1994) specifies two notable efferent pathways of the vagus, or parasympathetic nerve, to the heart. One pathway, originating from the dorsal motor nucleus, mediates decreases in heart rate, resulting in decreases in emotional arousal. Alternatively, a pathway originating in the nucleus ambiguus inhibits vagal activity, resulting in increases in emotional arousal and sympathetic activity (e.g., arousal, panic, anxiety). Taken together, these two pathways mediate responses to threatening and emotional stimuli by exerting opposing actions on cardiac activity. "Vagal tone" is a term that refers to the mediation of these two pathways and their influence on cardiac activity (Beauchaine, 2001). Increases in vagal tone indicate decreases in emotional arousal; decreases in vagal tone, also called "vagal withdrawal" or "parasympathetic withdrawal", indicate increases in emotional arousal. In contrast, sympathetic activity mediates physiological mobilization in response to impending threat. Thus, increases in sympathetic activity indicate increases in emotional arousal 
and decreases in sympathetic activity indicate decreases in emotional arousal (e.g., Porges, 1997; Porges, 2009).

Psychophysiologists highlight the importance of examining distinct measures of parasympathetic and sympathetic responding because these systems can interact to produce differential effects on autonomic activity (Berntson, Cacioppo, \& Quigley, 1991). Weinberg and colleagues' (2009) study involved clear and distinct indices of both parasympathetic and sympathetic branches. However, it only examined these two constructs across two data points. Whereas Scott and colleagues (2012) examined changes in emotional arousal over more data points, they did not examine any parasympathetic measures of emotional arousal. Hazlett and colleagues' (2012) study is an important contribution because it is the only one to examine central nervous system functioning, but it is unclear whether emotional recovery can be assessed without terminating emotional stimuli. All of these studies reflect rigorous examinations of delayed emotional recovery or related processes, but could be improved through continuous assessment of both parasympathetic and sympathetic branches of the autonomic nervous system after (and not during) the presentations of emotional stimuli.

Emotion specificity in delayed emotional recovery. All of the aforementioned studies share an additional limitation: the failure to examine the specificity of delayed emotional recovery across discrete emotions. Extant data indicate that emotional processes in BPD (e.g., reactivity) may be specific to some emotions (e.g., anxiety, anger), rather than pervasive across all emotions (Koenigsberg, Harvery, Mitropoulou et al., 2002). It is thus plausible that emotional recovery may also be emotion-specific. All of the aforementioned studies have failed to examine whether delayed emotional recovery in BPD is specific to the emotion elicited or pervasive across all emotions. Rather, these studies have either elicited one discrete emotion only (e.g., 
anger; Jacob et al., 2009), or engaged participants in generalized negative emotion inductions (e.g., Gratz et al., 2010; Hazlett et al., 2012; Scott et al., 2012; Weinberg et al., 2009).

Generalized inductions can elicit a range of emotions, and it thus remains unclear whether delayed emotional recovery in BPD is specific to the emotion elicited or pervasive across emotions.

BPD-relevant confounds. In addition to assessing for emotion specificity, it is important to rule out plausible alternative explanations when examining delayed emotional recovery. Two key potentially confounding factors in this research are heightened emotional reactivity and state-dissociation. As Gratz and colleagues (2010) showed, when reactivity to emotion inductions is not accounted for, the appearance of delayed emotional recovery may be artificially inflated. As some studies have failed to account for changes in emotional arousal during the induction when examining changes from the emotion induction to the recovery period (e.g., Hazlett et al., 2012), reactivity and delayed emotional recovery may be confounded.

Some of the aforementioned studies (e.g., Gratz et al., 2010; Jacob et al., 2009) could also be improved by controlling for state dissociation (i.e., derealization, depersonalization, absorption, amnestic experiences; Bernstein \& Putnam, 1986). Research shows that individuals with BPD exhibit high levels of dissociative experiences (Ross, 2007). Further, dissociation can attenuate self-reported and psychophysiological responding in BPD (Ebner-Priemer et al., 2007; Ludascher, Valerius, \& Stiglmayr, 2010). It is possible that the aforementioned studies did not find evidence of delayed emotional recovery in BPD because dissociation dampened emotional responding, thereby resulting in the appearance of a normal emotional recovery in BPD. Studies examining delayed emotional recovery in BPD should control for the influence of dissociation to 
fully disentangle these phenomena. Finally, there is a fifth limitation to the literature on delayed emotional recovery in BPD: the failure to examine the influence of emotion regulatory attempts. Difficulties with Emotion Regulation in BPD

A key component of Linehan's (1993) theory is that emotion processes such as delayed emotional recovery are coupled with difficulties with emotion regulation. Several studies show that individuals with BPD have difficulties regulating their emotions (e.g., Conklin, Bradley, \& Westen, 2006; Ebner-Priemer et al., 2007; Ross, 2007). As indicated above, theoretical models of BPD (Linehan, 1993) suggest that all BPD-relevant behaviours are either direct consequences of emotion dysregulation or maladaptive attempts to regulate emotion (i.e., employment of maladapative emotion regulation strategies). A maladaptive emotion regulation strategy is one that, although perhaps effective in altering the emotional experience in the short-term, entails negative long-term consequences. Non-suicidal self-injury (i.e., NSSI) and suicidality (e.g., suicidal ideation, suicide attempts) are conceptualized as maladaptive emotion regulation strategies that are particularly salient in BPD research and clinical literature (e.g., APA, 2000; Brown, Comtois, \& Linehan, 2009).

NSSI, suicidal ideation, and delayed emotional recovery. Over 70\% of BPD women have had multiple episodes of NSSI, and 90\% have self-injured at least once (Zanarini, Frankenburg, Jager-Hyman, Reich, \& Fitzmaurice, 2008). NSSI is linked to eating disorder symptomotology (Sansone \& Sansone, 2011), alcohol and substance use problems (Wong, Leung, Chow, Kam, \& Tang, 2010), and increased health-care utilization in BPD groups (Sansone, McLean, \& Widerman, 2008). Further, approximately $80 \%$ of BPD women report at least one suicide attempt, with $60 \%$ reporting multiple suicide attempts (Zanarini, Frankenberg, Jager-Hyman, Reich, \& Fitzmaurice, 2008). 
Although NSSI and suicide attempts both involve physically damaging acts to the self, they are highly distinct constructs. Research shows that intention to die distinguishes selfinjurers from those attempting suicide (Nock \& Kessler, 2006). Furthermore, NSSI is primarily motivated by attempts to distract oneself, generate normal feelings, express anger, or punish oneself, and suicide attempts are primarily motivated by efforts to escape or the perception that others are "better off without them" (Brown, Comtois, \& Linehan, 2002; Muehlenkamp \& Gutierrez, 2004).

There is evidence that NSSI and suicidal ideation may function to regulate emotions in BPD. For example, Welch, Linehan, Slyvers, Chittams, and Rizvi (2008) read participants with BPD imagery scripts describing personally-relevant scenes in which they engaged in an act of NSSI, accidentally died, or in which they attempted suicide. This induction involved four stages for each event: a setting leading up to the event, behaviours and reactions leading up to the event, the event itself (i.e., NSSI, accidental death, suicide attempt), and consequences after the event (i.e., reactions, behaviours). Parasympathetic (RSA) and sympathetic (SCR) indices of emotional responding were measured throughout and general self-reported subjective negative emotions were measured at each stage. These authors found that individuals with BPD displayed decreases in SCR and subjective negative emotions from the NSSI and accidental death events to the consequences after the event. However, individuals did not experience significant changes between these stages during the suicide attempt imagery. The authors posit that the accidental death scripts functioned as a form of suicidal ideation that, similar to models of self-harm, reduced negative emotions. These findings show that NSSI and suicidal ideation may function as emotion regulation strategies in the context of BPD. 
Given that NSSI and urges to commit suicide may function as key emotion regulation strategies in BPD, it follows that these strategies may modulate delayed emotional recovery in this population. Indeed, it is possible that these strategies are engaged because they quicken emotional recovery. Though it is intuitively appealing, only one study has attempted to examine this. Reitz and colleagues (2012) exposed individuals with BPD and HCs to a stress induction involving an arithmetic task and negatively valenced images and monitored heart rate and selfreported aversive inner tension at eight time-points across a 30 minute period following the induction. After inducing stress in both groups, the authors either made an incision into the arms of participants to mimic self-injurious behaviour or exposed participants to a "sham" condition in which the blunt portion of a scalpel touched their arm. All participants went through both conditions. Consistent with findings from Welch and colleagues' (2008) study, the BPD group showed decreases in heart rate after the incision but not after the sham and also demonstrated lower average heart rate over time after the incision compared to the sham condition. Conversely, the HC group did not show decreases in heart rate after the incision compared with sham or over time after the incision relative to the sham. These findings suggest that NSSI may result in quicker reductions in negative emotionality in the BPD group only. Reitz and colleagues' (2012) study is thus an important one in terms of examining the potential role of emotion regulation strategies in altering emotional recovery in BPD. However, examining the impact of NSSI on emotional recovery across discrete emotions could further strengthen the study.

In sum, the extant data on delayed emotional recovery in BPD is both scarce and conflicting; while some studies may provide evidence for this phenomenon in BPD (e.g., Hazlett et al., 2012), others do not (e.g., Gratz et al., 2010; Jacob et al., 2009; Scott et al., 2012; 
Weinberg et al., 2009). Further, the current literature would benefit from addressing the following shortcomings: (1) examining emotional recovery across more data points, (2) examining emotional recovery as indexed by parasympathetic and sympathetic markers, (3) examining emotional recovery across specific emotions, (4) controlling for heightened reactivity and state dissociation, and (5) examining the potential modulating affect of emotion regulatory attempts (i.e., NSSI and suicidal ideation). The present study aims to address all of these limitations by examining (a) whether individuals with BPD demonstrate a slower emotional recovery relative to HCs as indexed by self-report, RSA, and SCR across three discrete emotion inductions (i.e., fear, anger, and sadness inductions) and (b) whether elevations in urges to engage in NSSI and urges to commit suicide modulate emotional recovery across groups.

\section{Hypotheses}

Hypothesis 1a: Emotional recovery (physiological). After each emotion induction, the BPD group will show a slower emotional recovery as indicated by slower rates of increase in RSA and decrease in SCR over a 5-minute washout period compared with the HC group.

Hypothesis 1b: Emotional recovery (self-report). After each emotion induction, the BPD group will show a slower emotional recovery as indicated by less change in self-reported emotional intensity from immediately after the emotion induction to after the washout period compared with the HC group.

Hypothesis 2a: Emotion regulation strategies (self-report). After each emotion induction, the BPD group will show higher urges to engage in NSSI and urges to commit suicide compared with HCs.

Hypothesis 2b: Emotional recovery and emotion regulation strategies (physiological). In the BPD group only, high urges to engage in NSSI and urges to commit suicide will predict 
faster returns in the recovery period after the emotion induction as indicated by greater rates of increase in RSA and decrease in SCR over the 5-minute washout period.

\section{Hypothesis 2c: Emotional recovery and emotion regulation strategies (self-report).}

In the BPD group only, high urges to engage in NSSI and urges to commit suicide will predict faster returns in the recovery period after each emotion induction as indicated by larger changes in self-reported emotional intensity from immediately after the emotion induction to after the washout period.

\section{Method}

\section{Participants}

Participant demographics are presented in Table 1. Individuals with BPD $(n=20)$ and HCs $(n=20)$ between the ages of 18 and 45 were recruited from the community through flyers at relevant healthcare outlets (e.g., community hospitals), Internet postings, and outreach to individuals who were already engaged in treatment for BPD at the University of Washington Behavioural Research and Therapy Clinics. Individuals under the age of 18 were excluded from the study because of warnings against assigning adolescents and children personality disorder diagnoses (APA, 2000). HCs with any current Axis-I diagnoses were also excluded from the present study, and HCs reporting 4/9 criteria or endorsing either the self-harm/suicidality or the impulsivity criteria in the Structured Clinical Interview for Axis II Personality Disorders (SCIDII), BPD module (First, Spitzer, Gibbons, Williams, \& Benjamin, 1996) were also excluded to certify diagnostic divergence between groups. Included HCs were matched with the BPD group on age \pm 2 years given literature suggesting that age can influence psychophysiological recordings and that BPD features may change or decline with aging (Antelmi et al., 2004; Shea et al., 2009). The mean age of the BPD and $\mathrm{HC}$ groups were 23.55 and 23.30 , respectively, 
indicating that matching was successful across groups. Further, in order to avoid confounds of sex differences in the physiological data (Kring \& Gordon, 1998), only women were recruited for the study. Individuals who were colour-blind were excluded from the study because the task administered before and after each emotion induction involved the identification of coloured stimuli.

Insert Table 1 here

Given that co-morbidity is highly prevalent in BPD populations (Tadic, Wagner, Hoch et al., 2009), individuals with BPD with co-morbid diagnoses were included in the sample in order to increase generalizability. However, consistent with typical exclusion criteria used in the literature, participants with co-morbid diagnoses of schizophrenia, schizoaffective disorder, schizophreniform, bipolar disorder, and substance dependence were excluded from the study (e.g., Barnow et al., 2012). The prevalence of diagnostic comorbidities within the BPD group are presented in Table 2.

Insert Table 2 here

Psychotropic medication may interfere with physiological recordings (e.g., Yeragani, Pohl, Balon, \& Ramesh, 1992). Therefore, participants on any psychotropic medication other than selective serotonin reuptake inhibitors (SSRIs), which have been shown to have a more benign physiological profile (Licht, de Geus, van Dyck, \& Penninx, 2010), were excluded. Further, participants were excluded if they reported that they were taking major tranquilizers, 
antihistamines, or beta-blockers. Finally, participants with epilepsy or seizure disorder, heart disease, or asthma were also excluded because research shows that either these conditions, or common medications for them (e.g., carbamazepine, beta-blockers), are associated with alterations in heart rate variability recordings (Garrard, Seidler, McKibben, McAlpine, \& Gordon, 1992; Niemela, Airaksinen, \& Huikuri, 1994; Tomson \& Kenneback, 2007).

Power analyses. Although no literature to date has examined the specific relationships under investigation in the present study, similar research was used to gauge the appropriate sample size required for a meaningful effect in emotional recovery across groups. With respect to within-group analyses, Welch and colleagues (2008) reported changes in urge to engage in NSSI from a baseline to after being read the self-injury script with an effect size of $d=.94$. This effect size indicates that a sample size of $n=14$ per group will yield enough statistical power to obtain a similar effect. Gratz, Rosenthal, Tull, Lejeuz, and Gunderson (2010) reported an effect size of $\eta_{p}^{2}=.30$ for a group X time interaction on changes in shame after negative mood emotion. This effect size indicates that in order to achieve the desired power of .85, a total sample of $N=37$, or approximately $n=18$ per group, is required. Thus, based on the aforementioned literature, a sample size of 20 individuals per group was considered likely sufficient to obtain adequate within and between groups effects.

\section{Measures}

Screening and descriptive measures. The Demographic Data Survey (DDS; Linehan, 1982) is a measure of a wide range of demographic information such as height, weight, age, ethnicity, average income, and marital status. The DDS was used to obtain basic demographic information of all participants.

All participants were administered a Structured Clinical Interview for Axis I DSM-IV 
Disorder-Patient Edition (i.e., SCID; First, Spitzer, Gibbon, \& Williams, 1995) in order to identify any Axis I disorders. The SCID-I has excellent psychometric properties and research supports its inter-rater reliability. For example, Kappa values are typically in the range of .83 for the SAD module (Lobbestael, Leurgans, \& Arntz, 2010) and .80 for the Major Depressive Disorder Module (Zanarini, Skodol, Bender, et al., 2000).

All participants were also administered the SCID-II, BPD module (First et al., 1996). There is substantial research supporting the SCID-II as a reliable and valid diagnostic tool for BPD. For example, Kappa values for the BPD module are typically in the range of .91 (Maffei, Fossati, Agostoni, et al., 1997). Both the SCID-I and the SCID-II were conducted by a Master'slevel psychologist who was trained to administer the SCID-I and SCID-II reliably with other assessors as part of larger treatment trials within the University of Washington Behavioural Research and Therapy Clinics.

Covariate. The Dissociative State Scale (DSS; Stiglmayr et al., 2001) was used as the index of dissociation. The DSS is a 20 -item self-report inventory designed to measure both somatic (i.e., in pain perception, speech generation, vision, hearing, or motor control) and psychological (i.e., derealization, depersonalization, absorption, amnesia, and awareness disturbances) dissociation. Participants were asked to rate the extent to which they experienced each item "just now". Higher scores indicate higher severity of dissociative states. Research supports the use of the DSS as a measure of state dissociative phenomena (e.g., Stiglmayr et al., 2001).

Emotion regulation strategy measures. The Visual Analogue Scale (VAS; Haines, Williams, Brain, \& Wilson, 1995) was used to measure participant's urges to engage in NSSI and to commit suicide. Participants indicated their reactions on a continuous VAS with bipolar 
ends of 1 (no urge) to 100 (strong urge) demarcated to indicate the intensity of their urges. Prior research shows that the use of a VAS is a legitimate way of measuring subjective experiences in clinical psychological research (McCormack, Horne, \& Sheather, 1988).

Self-reported arousal. The VAS (Haines, Williams, Brain, \& Wilson, 1995) was also used to measure individual's self-reported emotional states. Participants rated their subjective reactions on a scale from 1 to 100 on three bipolar dimensions: calm-angry, unafraid-afraid, happy-sad. Higher scores reflect higher levels of negative experience.

Physiological arousal (RSA). Respiratory sinus arrhythmia (RSA) was used as the index of parasympathetic responding. Mindware Technologies HRV 2.33 (Mindware Technologies Ltd., 2011a) software was used to apply a validated algorithm to detect variable ECG R-wave time series (RR) intervals using the overall distribution of RRs. This process contributes to detecting and editing artifacts (Bernston, Quigley, Jang, \& Boysen, 1990). Spectral analysis was then used to decompose the R-wave time series into three frequency ranges: high-frequency (greater than $.15 \mathrm{~Hz})$, mid-frequency $(0.04 \mathrm{~Hz}$ to $0.15 \mathrm{~Hz}$ ), and low-frequency (less than 0.04 Hz). In line with Berntson, Bigger, Eckberg and colleagues (1997), RSA was measured through a high-frequency band of spectral analysis. Mindware Technologies HRV 2.33 software was used to calculate high-frequency spectral densities across 30 second epochs.

Physiological arousal (SCR). The number of non-specific skin conductance responses (SCRs) was measured as an index of sympathetic responding. SCR was collected using the BIOPAC 5-channel data acquisition system (Biopac Technologies, Model MP100, Goleta, CA). Two 6-mm electrodes (Biopac model TSD203) with electrolyte gel were placed on the medial phalanges of two fingers on the non-dominant hand in accordance with Fowles, Christie, Edelberg, Grings, Lykken, and Venables' (1981) recommendations. SCR data was digitized at 
1,000 samples per seconds with a gain of 1,000 using low- $(35 \mathrm{~Hz})$ and high- $(.05 \mathrm{~Hz})$ pass

filters.

Mindware Technologies EDA 2.40 program (Mindware Technologies Ltd., 2011b) was used to process the SCR data collected through the BIOPAC 5-channel system; a programmable rolling filter was used for artifact detection and editing. SCR was calculated as the total number of non-specific fluctuations exceeding $0.05 \mathrm{u} S$ across 1 minute epochs.

Emotion induction films. Gross and Levenson (1995) examined the efficacy of 250 films in eliciting several target emotions measured by intensity of emotions elicited and discreteness of responses from participants. The authors recommended two films per target emotion as the most evocative films to be used for emotion inductions. The present study used the recommended films from this report that reliably elicited fear, anger, and sadness. The fear film clip is a 3:29 minute scene from "Silence of the Lambs" (Saxon, Utt, Bozman, \& Bemme, 1991) that shows a woman being chased by a male predator in a dark basement. The anger film clip is a 4:06 minute excerpt from "My Bodyguard" (Devlin \& Bill, 1980) that depicts a teenage boy being victimized and bullied by another teenage boy. Finally, the sadness film clip is a 2:51 minute excerpt from the film "The Champ" (Lovell \& Zeffirelli, 1979), depicting a young boy crying when his father dies. All film clips were shown on a 42-cm X 32-cm computer monitor. Order of film presentation was counterbalanced across participants.

\section{Procedure}

Participants who indicated interest were contacted via telephone and informed of the nature of the study, requirements of participants, and were briefly screened for exclusion criteria. Those who did not meet exclusion criteria were invited to participate in the diagnostic interviews (i.e., SCID-I and SCID-II). Prior to answering any diagnostic or demographic questions, 
participants were required to provide informed consent. Participants were instructed to avoid the ingestion of caffeine, tobacco or other stimulants before participating in the experimental paradigm.

First, participants viewed one of the emotion induction films (i.e., fear, sadness, or anger $)^{1}$, depending on the counterbalancing order. Following the viewing of the film, participants rated their dissociative state, current emotional intensity, and urges to engage in NSSI and to commit suicide. Participants then engaged in a 5 minute low-demand, neutrally-valenced cognitive task in which they count the number of times a given colour appears on the screen (Jennings, Kamarck, Stewart, Eddy, \& Johnson, 1992). During this 5 minute “washout” period, emotional recovery from the emotion induction was assessed. This task was selected to assess emotional recovery in favour of a resting period in which participants sit quietly with no stimulus because clinical experience suggests that BPD individuals often experience high levels of distress when sitting idle for extended periods. Research shows that shorter periods of engagement with this low-demand cognitive task (e.g., 10 minutes) are equal or superior to longer resting periods in achieving physiological stability (Jennings et al., 1992). Immediately after the washout period, participants rated their current emotional intensity and urges to engage in NSSI and to commit suicide.

${ }^{1}$ The data analyzed in the proposed study is previously collected data from a study examining emotional reactivity in BPD (Kuo \& Linehan, 2009). The parent study included a fourth, neutral emotion induction. Further, as the original intent was not to examine emotional recovery, the study terminated after the last emotion induction and thus did not assess a final washout period (e.g., a period of emotional recovery after the emotion induction). Consequently, in the present study, approximately between $17 \%$ and $30 \%$ of the outcome observations are missing. 
Participants then viewed the next film and repeated the procedure specified above until all three films were viewed. Participants were physiologically monitored throughout the entire session. Figure 1 is a visual schematic of the experiment. All experimental procedures were conducted in a sound-attenuated room maintained at room temperature (20 degrees Celsius). Following the experimental paradigm, participants were debriefed and compensated. Multivariate analyses of variance were employed to test for order effects. There were nonsignificant effects of order of film presentation or group X order interactions on RSA, SCR, and self-reported emotional intensity for the fear, anger, and sadness data. This indicates that counterbalancing was successful, and the order of film presentation did not significantly bias results.

Insert Figure 1 here

\section{Data Analytic Strategy}

\section{Comparing Data Analytic Strategies}

Hierarchical linear modeling (i.e., HLM; Singer \& Willett, 2003; Woltman, Feldstain, McKay, \& Rocchi, 2012) was the preferred data analytic method for the psychophysiological results because it involves (a) examining relationships between predictors and outcomes over a systematic time course (e.g., over 30-second epochs across the 5-minute washout period), (b) multiple observation points, (c) nested levels of modeling, and (d) accommodates missing data. However, HLM is only an appropriate strategy when the outcome measures are linear over time (Singer \& Willett, 2003). Otherwise, a Mixed Model Analyses of Variance (i.e., MMANOVA; Littell, Milliken, Stroup, \& Wofinger, 1996) is a more appropriate analysis because time is 
considered a categorical variable and a linear trend over time is not assumed. In order to determine whether HLM was an appropriate data analytic strategy for the data, line graphs were generated examining each outcome variable of interest (RSA, SCR) over time for each emotion (fear, anger, sadness). Visual inspection suggested that all variables are approximately linear over time, however, statistical analyses were undertaken to more reliably examine this.

In order to statistically determine which data analytic strategy is the most appropriate for the present study, statistical procedures were undertaken in line with Verbeke and Molenberghs' (2000) guidelines. MMANOVA analyses were conducted in which time was considered a categorical versus a continuous variable. If the -2 Restricted Log Likelihood values are smaller for the model in which time is considered continuous than the model in which time is considered categorical, HLM is a more appropriate data analytic strategy. For all variables of interest, the -2 Restricted Log Likelihood values were smaller for the former model, indicating that HLM is the most appropriate data analytic strategy.

In light of the above findings, HLM analyses were conducted for each emotion induction (fear, anger, sadness). The first level of the model (i.e., level-1 submodel) involves examining inter-individual change over 30 second epochs across the 5-minute post washout period (i.e., emotional recovery). Time was the only predictor entered in level-1. The level-1 submodel is exemplified in formula 1.1 wherein $\pi_{0 i}$ reflects an individual's arousal during the emotion (e.g., RSA, SCR), $\pi_{1 i}$ reflects an individual's change over the 30 second epochs following the emotion induction, and $\varepsilon_{i j}$ reflects variance not captured by the proposed model.

$$
\text { (1.1) } \mathrm{Y}_{i j}=\pi_{0 i}+\pi_{1 i} T I M E_{i j}+\varepsilon_{i j} \text {. }
$$

Within-individual differences are reflected in the level-2 submodel. In the level-2 submodel, four predictors were specified. First, group status was entered as a predictor in order 
to examine group differences in overall physiological arousal across the 5 minute washout period. Second, urges to engage in NSSI and urges to commit suicide immediately after the emotion induction were entered as predictors of overall physiological arousal across the 5 minute washout period. These predictors were treated as time-invariant predictors because they were not assessed continuously over time. Third, in order to test hypothesis 1a, group X time interactions were tested in order to examine whether there were group differences in rates of change in physiological arousal during the 5 minute washout period. Finally, in order to test hypothesis $2 \mathrm{a}$ and $2 \mathrm{~b}$, three-way interactions between group $\mathrm{X}$ urge to engage in NSSI $\mathrm{X}$ time, and group $\mathrm{X}$ urge to commit suicide $\mathrm{X}$ time were tested. These analyses were conducted for each index of physiological arousal (RSA, SCR) across each emotion induction (fear, anger, sadness).

Covariates. In order to ensure that arousal during the washout period is not accounted for by heightened emotional reactivity (e.g., Gratz et al., 2010), change scores between average emotional arousal during the washout period that occurred prior to the emotion induction and average emotional arousal during the emotion induction were calculated. These change scores were entered into the level-2 submodel as covariates. Further, in order to ensure that the findings in the present study were not modulated by state-dissociation, average levels of dissociation immediately after the emotion induction as indicated by the DSS were also entered into the model as a covariate. Similar to the group, urges to engage in NSSI and urges to commit suicide variables, these covariates were treated as time-invariant predictors because they were not assessed continuously over time.

The proposed study used a restricted likelihood maximum estimation approach to HLM because the maximum likelihood estimates are robust in instances in which the assumption of multivariate normality is violated (Patterson \& Thompson, 1971). Chi-square tests were run to 
determine the best fitting covariance structure for each outcome of interest. In these tests, the simplest model is chosen if the difference between the -2 Restricted Log Likelihood values is not statistically significant (Verbeke \& Molenberghs, 2000). These tests revealed that the best fitting model for RSA in the anger induction was the random intercept model. The data also indicated that random intercept and random slope (not correlated) was the best fitting model for RSA and SCR indices across all other emotion inductions.

Hypothesis 1b and 2c: Self-report data. Multiple regression analyses were conducted to test hypothesis $1 \mathrm{~b}$ and $2 \mathrm{c}$. Three analyses were run examining change in self-reported fear, anger, or sadness for the fear, anger, and sadness emotion inductions, respectively. That is, changes were only examined in the target emotion in each emotion induction. Change scores between the emotional intensity immediately after the emotional induction to the emotional intensity after the 5 minute washout period were entered as the outcomes. Group was entered as a predictor in the first step. Urges to engage in NSSI and to commit suicide immediately after the emotion induction were entered as predictors in the second step. In order to test for two-way interactions between group and the emotion regulation strategies, interaction terms were calculated by multiplying the group variable by the urge to engage in NSSI or to commit suicide, respectively, and entered into the third step. Though Kraemer and Blasey (2004) recommend that all predictors be centered by subtracting each variable from its median to reduce multicollinearity, the median for many of these measures was 0 (see Table 3 ). In order to center predictors, predictors were standardized by subtracting each variable from its mean rather than median.

Insert Table 3 here 
Each regression analysis across fear, anger, and sadness inductions revealed significant indications of multicollinearity despite efforts to center predictors. Further investigation revealed that the interaction terms were highly multicollinear with the other predictors. Table 6 reveals the correlations between, and the variance inflation factors and tolerance values for, urges to engage in NSSI, urges to commit suicide, and the interaction terms of these variables with the group variable. Tolerance values below 0.2 and variance inflation ratios above 10 indicate possible multicollinearity (Menard, 1995; Myers, 1990). As the data indicated that the interaction terms might significantly bias the model, they were excluded from the regression analyses. In the final regression analyses, the tolerance values and variance inflation factors for urges to engage in NSSI and to commit suicide ranged between .22 and .52 and 1.28 and 4.56, respectively. These statistics indicate that multicollinearity was likely no longer a problem. Furthermore, the DurbinWatson statistic ranged from 1.78 to 2.03 indicating that the assumption of independent errors in regression was likely also met.

\section{Insert Table 6 here}

\section{Results}

\section{Missing Data}

This data was derived from a larger dataset that was not originally collected to assess emotional recovery, and as a result, some data are missing (see Footnote 1). In light of this, missing data analyses were run in order to examine whether these limitations would significantly 
impact findings. For analyses pertaining to the fear induction, between $21.17 \%$ (RSA analysis) and $21.33 \%$ (SCR analysis) of the data for the psychophysiological analyses were missing and $7.50 \%$ of the data for the self-report analysis was missing. For analyses pertaining to the anger induction, between $12.33 \%$ (RSA analysis) and $14.77 \%$ (SCR analysis) of the data for the psychophysiological analyses were missing and $4.38 \%$ of the data for the self-report analysis was missing. For analyses pertaining to the sadness induction, $19.67 \%$ of the data for both the RSA and SCR psychophysiological analyses were missing, and $6.88 \%$ of the data for the self-report analyses was missing. Nine Little's MCAR tests were run, one for each analysis in the present study (i.e., examining RSA, SCR, and self-report indices across fear, anger, and sadness inductions). Of the nine analyses run, eight were statistically non-significant indicating that the data was missing at random. One statistically significant Little's MCAR test for the self-report data collected during and after the sadness induction indicated that the data for this analysis were not missing randomly, $\chi^{2}(2)=10.30, p=.006$.

\section{Descriptive Statistics}

Means, medians, and standard deviations for all self-report measures included in the study are presented in Table 3. Means and standard deviations for the psychophysiological data are presented in Table 4 . The SCR variable was highly positively skewed (skew statistic ranged from 1.14 to 1.91 across emotion inductions). In order to yield a more normal distribution, one unit was added to this variable, which was then logarithmically transformed (base 10). The transformed SCR variable yielded a more normal distribution (skew statistic ranged from .61 to .97 across emotion inductions). Further, as physiological data were analyzed in 30 second segments, the final segment of participant's data often did not contain 30 full seconds. SCR is sensitive to the length of the segment that captures it because it reflects a total score (i.e., the 
total number of SCRs) rather than an average score. In order to prevent the SCR variable from being affected by the length of the last segment, the number of SCRs in each segment was divided by the number of seconds in each segment to yield the ratio of SCR per second.

Insert Table 4 here

\section{Correlational Analyses}

Across each emotion induction, the average RSA, SCR, and self-reported emotional intensity that occurred during the emotion induction was significantly and positively correlated with average RSA, SCR, and self-reported emotional intensity respectively, during the washout period. Further, across all emotion inductions, urges to engage in NSSI and to commit suicide were significantly positively correlated ranging from $r=.57(p=.001)$ after the anger induction and $r=.98(p<.001)$ after the sadness induction. Urges to engage in NSSI and to commit suicide were not significantly correlated with any variables of interest across emotion inductions, except for self-reported emotional intensity (during the induction and the washout period) in the fear and anger inductions. Across all emotion inductions, parasympathetic (RSA) and sympathetic (SCR) indices of emotional responding were not correlated with each other during the inductions or during the washout periods. Across all emotion inductions, change in mean RSA from the washout period before the induction to the induction was not significantly correlated with mean RSA during the washout period. Changes in mean SCR from the washout period before the induction to the induction was significantly positively correlated with mean SCR during the washout period for the anger inductions only. Mean levels of dissociation during the emotion inductions were not correlated with outcomes. 


\section{Primary Outcomes}

Fear. There was a significant main effect of time predicting changes in $\operatorname{RSA}, F(1,26.94)$ $=10.01, p=.004$, such that RSA decreased over time during the washout period. However, time did not significantly predict changes in SCR during the washout period, $F(1,39.53)=2.90, p$ $=.10$. There was no main effect of group on overall $\mathrm{RSA}, F(1,30.20)=3.04, p=.09$ or overall $\mathrm{SCR}, F(1,41.31)=.01, p=.91$, during the washout period. Further, there were no main effects of urges to engage in NSSI, $F(1,30.19)=.80, p=.38$, or to commit suicide, $F(1,30.15)=.41$, $p=.53$, predicting overall RSA during the washout period. There were also no main effects of urges to engage in NSSI, $F(1,41.27)=.88, p=.36$, or urges to commit suicide, $F(1,41.15)$ $=.31, p=.58$, predicting overall SCR during the washout period (See Table 5).

There was a significant group $\mathrm{X}$ time interaction predicting both changes in $\mathrm{RSA}, F(1$, $26.91)=5.02, p=.03$, and SCR, $F(1,39.44)=8.71, p=.005$, during the washout period. In addition, there was a significant three-way group $\mathrm{X}$ time $\mathrm{X}$ urge to commit suicide interaction, $F$ $(2,27.25)=3.29, p=.05$, and a marginally significant three-way group $\mathrm{X}$ time $\mathrm{X}$ urge to engage in NSSI interaction, $F(1,39.77)=3.72, p=.06$, predicting changes in SCR during the washout period.

Figure 2 illustrates the interaction between group and time predicting changes in RSA during the washout period. Post-hoc t-tests examining changes in RSA over time (from the beginning of the washout period to the end) within each group (not between groups) revealed that RSA decreased over time for the BPD group, $t(26.45)=-3.38, p=.002$, but did not change for the HC group, $t(27.80)=-.77, p=.45$. Figure 3 illustrates the interaction between group and time predicting changes in SCR during the washout period. Post-hoc t-tests examining changes in SCR over time (from the beginning of the washout period to the end) within each group (not 
between groups) revealed that SCR did not change over time for the BPD group, $t(39.15)=.78$, $p=.44$, but decreased significantly for the $\mathrm{HC}$ group, $t(40.10)=-3.90, p<.001$.

Insert Figures 2, 3 and 4 here

In order to disentangle the three-way interaction, means, medians, and standard deviations for urges to commit suicide immediately after the fear induction in both the BPD and $\mathrm{HC}$ group were examined. In the $\mathrm{HC}$ group, the mean and standard deviation of urge to commit suicide indicated little to no elevation in this variable $(M=.13$, median $=0, S D=.52)$ in contrast to the BPD group $(M=20.69$, median $=5.00, S D=25.24)$. Thus, the relationship between urge to commit suicide immediately after the fear induction and change in SCR during the washout period that followed was examined in the BPD group only.

Next, the BPD group was divided into high versus low groups based on a median split in urge to commit suicide. Figure 4 shows the relationship between SCR and time in individuals high versus low in urges to commit suicide. Post-hoc contrasts compared estimate statistics for rates of change in SCR for the two groups. In the low suicide group, the estimate statistic was positive $(.0003, S E=.0003)$, indicating a .0003 unit increase in SCR for each unit increase in time. In the high suicide group, the estimate statistic was negative $(-.0003, S E=.0007)$, indicating a .0003 unit decrease in SCR for each unit increase in time.

Insert Table 5 here 
Self-report data. Neither step one, $F(1,26)=1.76, p=.20$, in which group was the only predictor nor step two, $F(3,24)=1.18, p=.34$, in which urges to engage in NSSI and urges to commit suicide were entered into the model as predictors, resulted in statistically significant improvements to the model. Thus, the proposed model did not significantly predict changes in self-reported fear from immediately after the fear induction to self-reported fear after the 5 minute washout period. No coefficients were significantly predictive of changes in self-reported fear (see Table 7).

Insert Table 7 here

Anger. There were no significant main effects of time predicting changes in RSA, $F(1$, $22.58)=.04, p=.84$, or SCR, $F(1,44.29)=1.47, p=.23$, during the washout period after the anger induction. However, there was a significant main effect of group predicting overall RSA, $F$ $(1,51.35)=6.34, p=.02$, and overall SCR, $F(1,46.10)=5.46, p=.02$, during the washout period, such that the BPD group displayed lower RSA and higher SCR overall compared to the HC group. Further, there was a trend toward urges to commit suicide immediately after the anger induction predicting overall RSA during the washout period, $F(1,50.83)=3.39, p=.07$, such that higher levels of urges to commit suicide were associated with lower levels of RSA. Urges to engage in NSSI did not predict overall RSA, $F(1,50.83)=2.40, p=.13$, or SCR, $F(1,45.72)$ $=.34, p=.56$ and urges to commit suicide did not predict overall SCR during the washout period, $F(1,45.72)=.48, p=.49$. There were no significant interactions (see Table 5).

Self-report data. Neither step one, $F(1,31)=.76, p=.39$, in which group was the only predictor nor step two, $F(3,29)=.62, p=.61$, in which urges to engage in NSSI and urges to 
commit suicide were entered into the model as predictors, resulted in statistically significant improvements to the model. Thus, the proposed model did not significantly predict changes in self-reported anger from immediately after the anger induction to self-reported anger after the 5 minute washout period. No coefficients were significantly predictive of changes in self-reported anger (see Table 7).

Sadness. There was a significant main effect of time predicting changes in RSA during the washout period after the sadness induction, $F(1,31.06)=7.61, p=.01$, such that RSA decreased over time. However, there was not a significant main effect of time predicting SCR during the washout period, $F(1,29.60)=1.56, p=.22$. There was also a main effect of group predicting overall RSA, $F(1,33.32)=5.78, p=.02$, such that the BPD group showed lower overall levels of RSA relative to HCs during the washout period. There was no significant main effect of group predicting overall SCR during the washout period, $F(1,31.39)=1.47, p=.23$. Further, results indicated a significant main effect of urges to commit suicide, $F(1,31.18)=4.02$, $p=.05$ on overall SCR, such that higher urges to commit suicide immediately after the sadness induction was associated with lower overall levels of SCR during the washout period. Additionally, there was a trend toward significance of urge to engage in NSSI, $F(1,31.18)=$ $3.85, p=.06$, on overall SCR. However, neither urges to engage in NSSI $F(1,33.21)=.57, p$ $=.46$, nor urges to commit suicide, $F(1,33.21)=.79, p=.38$, statistically significantly predicted overall levels of RSA during the washout period. There were no significant interactions (see Table 5).

Self-report data. Neither step one, $F(1,27)=1.29, p=.26$, in which group was the only predictor nor step two, $F(3,25)=1.16, p=.35$, in which urges to engage in NSSI and urges to commit suicide were entered into the model as predictors, resulted in statistically significant 
improvements to the model. Thus, the proposed model did not significantly predict changes in self-reported sadness from immediately after the sadness induction to self-reported sadness after the 5 minute washout period. No coefficients were significantly predictive of changes in selfreported sadness (see Table 7).

\section{Discussion}

The present study was the first to directly test Linehan's (1993) theory of delayed emotional recovery after provocation in BPD across specific emotions, using a comprehensive assessment approach. The BPD group exhibited decreases in parasympathetic responding (RSA) and did not show changes in sympathetic responding (SCR) during the washout period after the fear induction. Conversely, the HCs did not show changes in parasympathetic responding and exhibited decreases in sympathetic responding after the fear induction. Results also showed that only the BPD group exhibited urges to commit suicide after the fear induction. Further, within the BPD group, those higher in urges to commit suicide showed decreases in sympathetic arousal over time after the fear induction, whereas those with low urges to commit suicide showed increases in sympathetic arousal over time.

Our findings do not support delayed emotional recovery or the modulating effect of NSSI or suicidal urges on this process after either anger or sadness inductions. However, urges to commit suicide immediately after the sadness induction significantly predicted SCR, such that higher urges to commit suicide were linked to lower SCR on average after the induction. Finally, there were no significant self-report findings across any inductions.

\section{Delayed Emotional Recovery and BPD}

In the current study, individuals with BPD failed to emotionally recover and even showed increases in emotional arousal after the fear induction. As decreases in RSA is indicative of 
greater parasympathetic withdrawal or increased arousal, the RSA data indicate that the BPD group became more aroused over the washout period after the fear induction, whereas the $\mathrm{HC}$ group did not change. Inspection of the RSA means throughout the study showed that the BPD group experienced decreases in mean levels of RSA from the before the fear induction to during the fear induction. These results suggest that the BPD group continued to demonstrate increases in emotional arousal as indicated by continued decreases in RSA after the termination of the emotional stimulus (the fear film), whereas the HC group did not. The RSA data thus indicate that the BPD group did not emotionally recover at all but rather continued to experience increasing emotional arousal even when the emotion induction stopped. Conversely, the SCR data supports the notion of slow (or no) emotional recovery in BPD and suggests that individuals with BPD did not show changes in emotional arousal after the fear induction, whereas HCs showed decreases in arousal over time (as indicated by decreased SCR). Taken together, the RSA and SCR data suggest that individuals with BPD are in the least failing to "emotionally recover" after the fear induction and may even be getting more aroused.

It is unclear why these individuals either get worse or do not recover as quickly after the termination of the fear stimulus compared with HCs. Emerging research suggests that individuals with BPD display elevated negative emotional intensity at baseline, and it is possible that sitting idle for long periods of time may actually be distressing for this population (Ebner-Premier et al., 2007; Gratz et al., 2010). This research is in contrast to the notion that resting periods accommodate a reduction in emotional arousal over time. It is possible that resting periods differentially influence BPD groups relative to HCs, such that they increase or maintain arousal in individuals with BPD and reduce emotional arousal in HCs. Any emotional recovery that may occur following the termination of an emotion induction may consequently be counteracted by 
unique and independent distress brought on by the resting periods. Consequently, the resting period may inadvertently serve as a new emotion induction. In the present study we attempted to circumvent this potential confound through the implementation of a "washout" period rather than a resting period in which participants sit idly with no stimuli. Research shows that distraction may be an effective form of emotion regulation in BPD (Jacob et al., 2011). The washout period was selected over a resting period because it involved a mildly distracting task, and may have allowed for more reductions in emotionality over time than a resting period might in a BPD group. However, it is possible that the washout period was not potent enough to ameliorate the potential distress brought on by resting periods in this group.

It is also possible that individuals with BPD experience extended or delayed emotional processes. Individuals with BPD may display temporally extended emotional responses, such that the peak intensity of their emotional responses may occur later than that of HCs. This would account for why responding in RSA continued into the washout period for the BPD group but not the $\mathrm{HC}$ group. Assessing emotional recovery may thus require longer periods of time than was allotted in the present study because the holistic emotional response process is delayed in this group. Further, given that parasympathetic and sympathetic branches are only loosely coupled (Berntson et al., 1991), the discrepancies between these two indices may suggest that some branches of the autonomic nervous system (i.e., parasympathetic) may take longer to undergo full emotional trajectories then others (i.e., sympathetic).

Additionally, elevations in emotional arousal (e.g., fear) may trigger secondary processes in this group that function to maintain or even increase emotional responding. Selby and Joiner's (2009) emotional cascades model in BPD posits that, after the presentation of an emotional stimulus, individuals with BPD engage in ruminative processes that increase or maintain 
emotional intensity for longer periods of time. For Selby and Joiner (2009), emotions are prolonged and intensified in BPD because secondary ruminative processes that are triggered by emotional stimuli maintain them. Individuals with BPD may thus be more likely to engage in ruminative processes that maintain or increase emotional arousal after the induction, resulting in the appearance of prolonged arousal.

A fourth and related explanation is that the emotions elicited are more likely to trigger secondary emotional processes in the BPD group than in HCs. The model of emotions that underpins many evidence-based treatments such as dialectical behaviour therapy (DBT; Linehan, 1993), assumes that emotions can lead to secondary emotions, which occur in response to the primary emotions, such as shame, guilt, or anger. It is possible that individuals with BPD are particularly vulnerable to the onset of secondary emotions compared to other groups. Thus, what may appear to be increases in emotionality after emotion inductions (RSA) or delayed emotional recovery (SCR) is actually accounted for by the onset of a secondary emotional process. Indeed, research shows that individuals with BPD are more likely to report the presence of multiple emotions than HCs (Ebner-Priemer et al., 2007). However, no studies have fully disentangled the temporal onset of primary and secondary emotions in BPD relative to other groups, and so this explanation is largely speculative.

In addition, as noted, a vast array of research suggests that individuals with BPD habitually engage more generally maladaptive strategies (e.g., NSSI, suicide attempts) to regulate their emotions than others (Black, Blum, Pfohl, \& Hale, 2004). More effective emotion regulation strategies like cognitive reappraisal (i.e., altering appraisals of emotionally-charged situations to reduce their emotional impact; Gross \& John, 2003) also effectively alter negative emotionality for individuals with BPD when they are instructed to implement it (Schulze et al., 
2011). However, healthy populations volitionally and habitually implement these strategies significantly more than individuals with BPD (Salsman \& Linehan, 2012). Thus, HCs may more readily engage habitual and implicit emotion regulation strategies such as cognitive reappraisal to prevent increases in emotional arousal and facilitate emotional recovery. Conversely, individuals with BPD may have experienced increases or maintenance in emotional arousal because they could not engage in their respective habitual emotion regulatory attempts such as NSSI or suicidal attempts. This theorizing is in line with evidenced-based treatments for BPD such as DBT, which assumes that skill deficits in the engagement of more effective and adaptive emotion regulatory behaviours in BPD (Linehan, 1993). As the engagement of more "adaptive" emotion regulatory strategies were not examined in this study, this remains an open empirical question.

\section{Emotional Recovery and Emotion Specificity}

Failures to emotionally recover only occurred in the BPD group after the fear induction and not the anger or sadness inductions. Research shows that other components of emotion dysregulation in BPD (e.g., heightened emotional reactivity) may be specific to the emotion elicited (Gratz et al., 2010). The specificity of results in the present study is thus consistent with the broader literature on emotion dysregulation in BPD and with past research, which did not find evidence of delayed emotional recovery after an anger induction (Jacob et al., 2009). However, it is unclear why individuals with BPD would exhibit increased distress or failure to emotionally recover during the post-fear induction washout periods only, particularly given that the washout period after each induction was the same. Indeed, if individuals with BPD merely find washout periods distressing, the observed effects in the post-fear recovery period would be evident across all of the inductions. 
In addition, the fear induction may be particularly distressing for individuals with BPD. Indeed, NSSI and urges to commit suicide were higher in the BPD group immediately after the fear induction ( $M=18.61$ and 20.69, respectively) compared to the anger $(M=10.78$ and 13.00, respectively) and sadness inductions ( $M=8.29$ and 8.57 , respectively). One explanation for this discrepancy is that the fear induction was significantly more evocative than the other two inductions for individuals with BPD. The fear film depicts a woman being chased by a man and, given the high rates of sexual trauma in women with BPD (Zanarini et al., 2002; Zanarini \& Frankenberg, 1997), may have uniquely triggered distressing memories or thoughts for this population. If this is the case, it is logical that individuals would take longer to show decreases in emotional arousal over time. Research shows that trauma modulates other components of emotion dysregulation in BPD (Limberg, Barnow, Freyburger, \& Hamm, 2010). Trauma history may also be an undetected moderator of abnormalities in emotional recovery in individuals with BPD. Examination of trauma histories would need to be assessed in order to disentangle these phenomena.

Alternatively, the affective quality of fear may have a more discernable physiological profile than that of anger and sadness. Emotion theorists argue that basic emotions can be distinguished on the basis distinct neural and physiological correlates (Ekman \& Cordaro 2011). Further, emerging research shows that fear exerts different effects on RSA and sympathetic activity compared to both anger and sadness, but that anger and sadness do not differ from each other in their effects on parasympathetic and sympathetic arousal (Rainville, Bechara, Naqvi, \& Damasio, 2006). It is possible that fear produces changes in the parasympathetic and sympathetic components that are more amenable to the assessment tools used in the present study. Indeed, the "fight-or-flight" reaction associated with fear involves detectable changes in 
psychophysiological patterns (Lang, Davis, \& Ohman, 2000). Patterns of emotional responding not assessed in the present study may be more activated in anger and sadness such as electromyography, electroencephalography, or muscle tension.

It is also possible that fear is more likely to trigger maintenance processes that may underlie increases in distress during the washout period (RSA) or delayed emotional recovery (SCR). There is a wealth of research linking anxiety and rumination (Aldao, Nolen-Hoeksema, Schweizer, 2010; Thomsen, 2006), and rumination is perhaps particularly prevalent in the anxiety disorders literature. Fear may activate processes that maintain emotional responding such as rumination more so than anger or sadness. Relatedly, fear may activate secondary emotional responses (e.g., shame, guilt) that are mistakenly interpreted as continued emotional responding in the present study. Though intuitively appealing, substantially more research must disentangle the potential temporality of these processes and their impact on related emotional phenomena to corroborate this theorizing.

Psychophysiological and self-report discrepancies. It is unclear why the self-report data did not corroborate the psychophysiological findings. However, dissonance between indices of emotional responding, particularly self-report and psychophysiological data, is common across studies on BPD (e.g., Reitz et al., 2012; Schmahl et al., 2004; Welch et al., 2008). A wealth of research shows that individuals with BPD experience difficulties in the labeling and identification of their emotional experiences (Ebner-Premier et al., 2007; Hertel, Shuze, \& Lammers, 2009; Leible \& Snell, 2004; Webb, Miles, \& Sheeran, 2008). Individuals with BPD may thus be less able to identify subjective changes in their emotional experience relative to other groups, or may be less able to disentangle specific emotions via self-report. Further, the discrepancy in the present study and other studies using both self-report and psychophysiological 
assessment may also suggest that self-reported emotional arousal and psychophysiological emotional arousal are distinct constructs. Indeed, Gross \& Thompson (2007) highlight that the components of an emotional response (e.g., experiential, physiological, and behavioural) may not always consistently correlate but rather reflect distinct components of an overarching emotional experience. The findings in the present study, taken together with Gross \& Thompson's (2007) theorizing, underscore the importance of multi-faceted assessments of emotional arousal. Finally, it is possible that the sample size in the present study was too small to identify meaningful changes with a regression analysis. Statisticians suggest a sample size of $104+k$, where $k$ is equal to the number of predictors in the model, for sufficient statistical power to examine the contributions of individual predictors (Green, 1991). However, given the high prevalence of discordance between indices of emotional arousal, these findings likely fit into a broader literature underscoring the complexity and diversity of the facets of emotional experiencing.

\section{The Present Study in the Context of the Extant Literature}

The results of the present study both contradict and corroborate past research. The RSA data showing increases during washout period after the fear induction and SCR results showing delayed emotional recovery after the fear induction in BPD are in conflict with the bulk of the extant literature which does not support delayed emotional recovery, or continued increases in emotional arousal after emotion inductions in BPD (e.g., Gratz et al., 2010; Scott et al., 2012; Weinberg et al., 2009). Generalized inductions may elicit any number of negative emotions so it is unclear what emotions were assessed in these studies. This discrepancy limits the comparability of findings across studies. Unlike these studies, the present study utilized specific emotion inductions to induce discrete emotions. Indeed, the discordance in findings across emotion inductions in the present study underscores that emotion specificity is important in 
investigating this phenomenon. Further, many of the extant studies in the literature were based solely on self-report and, like the present study, did not find evidence of delayed emotional recovery using self-report indices. The present findings indicate the importance of comprehensive self-report and psychophysiological assessment. Weinberg and colleagues' (2009) findings may also differ from the present study because our sample was a clinical population rather than a community population elevated in BPD features. It is possible that increases or failures to decrease emotional arousal after emotion inductions are only evident in individuals with a BPD diagnosis.

\section{The Modulating Impact of Emotion Regulation Strategies on Delayed Emotional Recovery}

Results of the present study also suggest that individuals with BPD who show high urges to commit suicide after the fear induction show decreases in SCR over time more than those who do not. Further, urges to commit suicide after the sadness induction significantly predicted lower SCR in general, but not rate of change. These results are consistent with the literature on suicidal behaviour in BPD (Welch et al., 2008) that suggests that it can function as a maladaptive emotion regulation strategy in this group. Indeed, it is logical that the choice to engage in an emotion regulation strategy is not only determined by its ability to decrease negative emotionality but to do so in a timely manner. Though suicidal behaviour is undeniably maladaptive and a critical target for psychological interventions, it is unsurprising that emotion regulation strategies that can reduce negative emotionality faster like suicidal ideation are engaged in this population.

While urges to commit suicide did not modulate rate of change after the sadness induction, it predicted lower emotionality in general after the induction. It is possible that fear and sadness are more likely to be influenced by urges to commit suicide because they focus on 
attention towards the self. Conversely, the locus of attention may be externalized when individuals with BPD experience anger. If the cause of emotion is attributed to something external to the self, individuals may be more motivated to engage in antagonistic behaviour (e.g., fighting) than self-punishing or suicidal behaviour. Conversely, urges to commit suicide may function as an emotion regulation strategy for some emotions (e.g., fear or sadness) and contexts and not others. Emerging research suggests that the use of emotion regulation strategies varies from context to context (Aldao \& Nolen-Hoeksema, 2012; Sheppes et al., 2011), and may be effective in some circumstances and not others. It follows, then, that individuals with BPD may selectively engage in suicidal ideation depending on a variety of parameters (e.g., emotion and context).

Non-suicidal self-injury and emotional recovery. The lack of significance for NSSI predicting emotional recovery is inconsistent with results from past studies such as that of Reitz and colleagues (2012). It is important to note that Reitz and colleagues (2012) inflicted an event that mimicked an act of NSSI in individuals with BPD rather than measuring their urges to engage in NSSI volitionally. Though Reitz and colleagues' (2012) research suggests that NSSI can reduce prolonged emotional responses in this group, these findings do not indicate whether or not individuals with BPD use NSSI in their daily lives towards this end. Indeed, the present study suggests that these individuals may be more likely to experience urges to commit suicide to regulate emotions. Alternatively, Brown and colleagues (2002) highlighted that the motivations for these two behaviours are distinct and that, unlike suicide attempts, NSSI is not engaged with the intent to die or escape life. A substantial breadth of literature suggests that anxiety and fear are maintained by avoidance and escape behaviours (e.g., Dymond \& Roche, 2009). Consequently, in light of Brown and colleagues' (2002) findings, it is logical that suicidal 
ideation would be engaged in favour of NSSI after an emotion is elicited (fear) that entails urges to escape.

\section{Clinical Implications}

Important clinical implications stem from the results of the present study. First, given that the results support delayed emotional recovery in BPD, clinical interventions should instruct individuals in skills that may quicken this process or aid individuals in tolerating prolonged emotional responses. Second, the present study suggests that at least some emotion regulation strategies such as suicidal ideation (though maladaptive) can increase the rate of emotional recovery in BPD. Evidence based treatments for BPD such as DBT assume that adaptive emotion regulation strategies (e.g., mindfulness) can be taught to individuals with BPD to replace more maladaptive ones (e.g., suicidal behaviour; Linehan, 1993). As the results in the present study suggest that emotion regulation strategies may improve the rate of emotional recovery, skills training in adaptive emotion regulation strategies may shorten periods of emotional distress in this group. In addition, individuals with BPD may benefit from learning skills that increase their ability to tolerate prolonged emotional responses such as the distress tolerance module in DBT (Linehan, 1993).

\section{Limitations}

This study reflects a strong and rigorous examination of emotional recovery in BPD. However, it has several notable limitations. First, the sample sizes in the present study were small. Our small sample size is compounded by the fact that the washout period was not assessed after the last emotion induction across all participants, resulting in a substantial amount of missing data. Furthermore, our sample is largely young and female. Though the homogeneity of our sample ensured increased internal consistency when comparing across groups, it limits the 
generalizability of our findings. Indeed, it is unclear whether these findings would replicate across sexes and the lifespan.

The present study is also limited by the short timeframe within which emotional recovery was assessed (5 minutes) and the few self-report data points through which one can infer emotional recovery. Though this is substantially longer than many extant studies examining this phenomenon in the literature (e.g., Hazlett et al., 2012), individuals with BPD may take more than 5 minutes to recover from emotion inductions. Future research should examine delayed emotional recovery over substantially longer periods of time and via continuous assessment of a variety of self-reported emotional responses.

\section{Directions for Future Research}

The present study highlights key future directions for both basic emotion scientists and clinical researchers. First, given that the results in the present study do not correlate across emotions, more research is needed to disentangle the psychophysiological profiles of discrete emotions both in HC and BPD groups. Discrete emotions may require different assessment tools, and the present study may have thus inappropriately matched assessment tools with the emotions elicited. This remains an open empirical question with relevance to most emotion researchers that utilize psychophysiological assessment.

In addition, while the present study is the first comprehensive test of delayed emotional recovery in BPD, future studies should attempt to replicate the present results. Further, future studies should attempt to do so using a range of different emotion inductions and assessments of emotional arousal to ensure that the present findings were not an artifact of the inductions used or the indices examined. Researchers should specifically monitor changes in self-reported emotional intensity continuously (e.g., through a continuous rating dial) rather than at 
intermittent periods that are spaced further apart. These changes would allow for the collection of more data points while emotional recovery is occurring, and consequently yield a more meaningful and comprehensive picture of changes in emotional responding.

Research supports the standardized inductions used in the present study as effective emotion inductions (Gross \& Levenson, 1995). However, this research is based on a healthy population. Future research should examine the validity of these inductions in BPD populations to examine whether the content of these films are perceived or interpreted by this group differently than by a healthy control group (e.g., serving as reminders of traumatic experiences). In addition, these processes should also be examined using different methodologies. In comparison to standardized inductions, a more ecologically valid assessment of delayed emotional recovery might induce emotions through personally-relevant or idiographic induction techniques (e.g., Pitman, Orr, Forgue, de Jong, \& Claiborn, 1987). Future research can also increase ecological validity by examining delayed emotional recovery in the everyday lives of individuals with BPD through ecological momentary assessment and ambulatory monitoring designs. It is possible that individuals with BPD do not always experience prolonged emotional responses per se, but rather engage in behaviours when emotionally dysregulated that inadvertently maintain emotional arousal (e.g., fighting with a partner). Examining emotional processes and corresponding behaviours in the day-to-day lives of these inductions can disentangle these processes.

Related, future studies examining the potentially modulating impact of emotion regulation on emotional recovery in BPD should examine a diverse range of emotion regulation strategies. BPD-relevant destructive emotion regulation strategies beyond NSSI and urges to commit suicide such as disordered eating and substance abuse (Sansone, Chu, Wiederman, \& 
Lam, 2011; Sansone \& Sansone, 2011) should be assessed. Further, future researchers should also examine emotion regulation strategies that are typically conceptualized as adaptive such as cognitive reappraisal (Gross \& John, 2003). Examining "adaptive" emotion regulation strategies may shed light on what HCs may do to facilitate emotional recovery that individuals with BPD may not do. These findings would also provide important implications for emotion regulation strategies that may be taught in clinical interventions to individuals with BPD.

In sum, the results of the present study represent a preliminary step in disentangling a complex web of emotionality and emotion regulation. The present study suggests that both problems with emotions proper (e.g., delayed emotional recovery) and the influence of maladaptive emotion regulation attempts are important to BPD etiology. However, though the present study provides some answers, a multitude of questions remain to be queried in order to determine the core etiology of BPD, and consequently develop more effective treatments. 


\section{References}

Aldao, A., \& Nolen-Hoeksema, S. (2012). The influence of context on the implementation of adaptive emotion regulation strategies. Behaviour Research and Therapy, 50, 493-501. doi:10.1016/j.brat.2012.04.004

Aldao, A., Nolen-Hoeksema, S., \& Schweizer, S. (2010). Emotion-regulation strategies across psychopathology: A meta-analytic review. Clinical Psychology Review, 30, 217-237. doi:10.1016/j.cpr.2009.11.004

American Psychiatric Association. (2000). Diagnostic and statistical manual of mental disorders (4th ed., text rev.). Washington, DC: Author.

Antelmi, I., De Paula, R. S., Shinzato, A. R., Araujo, C. P., Mansur, A. J., \& Grupi, C. J. (2004). Influence of age, gender, body mass index, and functional capacity on heart rate variability in a cohort of subjects without heart disease. The American Journal of Cardiology, 93, 381-385. doi: http://dx.doi.org/10.1016/j.amjcard.2003.09.065

Austin, M. A., Riniolo, T. C., \& Porges, S. W. (2007). Borderline personality disorder and emotion regulation: Insights from the polyvagal theory. Brain and Cognition, 65, 69-76. doi:10.1016/j.bandc.2006.05.007

Bagge, C., Nickell, A., Stepp, S., Durrett, C., Jackson, K., \& Trull, T. J. (2004). Borderline personality disorder features predict negative outcomes 2 years later. Journal of Abnormal Psychology, 113, 279-288. doi:10.1037/0021-843X.113.2.279

Barnow, S. S., Limberg, A. A., Stopsack, M. M., Spitzer, C. C., Grabe, H. J., Freyberger, H. J., \& Hamm, A. A. (2012). Dissociation and emotion regulation in borderline personality disorder. Psychological Medicine, 42, 783-794. doi:10.1017/S0033291711001917

Baskin-Sommers, A. R., Vitale, J. E., MacCoon, D., \& Newman, J. P. (2012). Assessing emotion sensitivity in female offenders with borderline personality symptoms: Results from a 
fear-potentiated startle paradigm. Journal of Abnormal Psychology, 121, 477-483. doi: $10.1037 / \mathrm{a} 0026753$

Beauchaine, T. P. (2001). Vagal tone, development, and gray's motivational theory: Toward an integrated model of autonomic nervous system functioning in psychopathology. Development and Psychopathology, 13, 183-214. doi:10.1017/S0954579401002012

Bernstein, E. M., \& Putnam, F. W. (1986). Development, reliability, and validity of a dissociation scale. Journal of Nervous and Mental Disease, 174, 727-735. doi:10.1097/00005053-198612000-00004

Berntson, G., Bigger, J., Eckberg, D., Grossman, P., Kaufmann, P., Malik, M., ... Van Der Molen (1997). Heart rate variability: Origins, methods, and interpretive caveats. Psychophysiology, 34, 623-648. doi:10.1111/j.1469-8986.1997.tb02140.x

Berntson, G. G., Cacioppo, J. T., \& Quigley, K. S. (1991). Autonomic determinism: The modes of autonomic control, the doctrine of autonomic space, and the laws of autonomic constraint. Psychological Review, 98, 459-487. doi:10.1037/0033-295X.98.4.459

Bernston, G., Quigley, K., Jang, J., \& Boysen, S. (1990). An approach to artifact identification: Application to heart period data. Psychophysiology, 27, 586-598. doi:10.1111/j.14698986.1990.tb01982.x

Black, D. W., Blum, N., Pfohl, B., \& Hale, N. (2004). Suicidal behavior in borderline personality disorder: Prevalence, risk factors, prediction, and prevention. Journal of Personality Disorders, 18, 226-239. doi:10.1521/pedi.18.3.226.35445

Brown, M. Z., Comtois, K. A., \& Linehan, M. M. (2002). Reasons for suicide attempts and nonsuicidal self-injury in women with borderline personality disorder. Journal of Abnormal Psychology, 111, 198-202. doi:10.1037/0021-843X.111.1.198 
Chapman, A. L., Dixon-Gordon, K. L., \& Walters, K. N. (2011). Experiential avoidance and emotion regulation in borderline personality disorder. Journal of Rational-Emotive and Cognitive-Behavior Therapy, 29, 35-52. doi:10.1007/s10942-011-0124-6

Cheavens, J. S., Strunk, D. R., \& Chriki, L. (2012). A comparison of three theoretically important constructs: What accounts for symptoms of borderline personality disorder? Journal of Clinical Psychology, 68, 477-486. doi:10.1002/jclp.20870

Conklin, C. Z., Bradley, R., \& Westen, D. (2006). Affect regulation in borderline personality disorder. Journal of Nervous and Mental Disease, 194, 69-77.

doi:10.1097/01.nmd.0000198138.41709.4f

Dawson, M. E., Schell, A. M., \& Filion, D. L. (2007). The electrodermal system. New York, NY, US: Cambridge University Press, New York, NY.

Devlin, D. (Producer), \& Bill, T. (Director). (1980). My bodyguard [Motion picture]. United States: Fox Hills Video.

Domes, G., Grabe, H., Czieschnek, D., Heinrichs, M., \&Herpertz, S. C. (2011). Alexithymic traits and facial emotion recognition in borderline personality disorder. Psychotherapy and Psychosomatics, 80, 383-385. doi:10.1159/000325828

Dymond, S., \& Roche, B. (2009). A contemporary behavior analysis of anxiety and avoidance. The Behavior Analyst, 32, 7-27. Retrieved from http://www.ncbi.nlm.nih.gov/pmc/articles/PMC2686994/.

Ebner-Priemer, Ulrich W., Kuo, J., Kleindienst, N., Welch, S. S., Reisch, T., ... Bohus, M. (2007). State affective instability in borderline personality disorder assessed by ambulatory monitoring. Psychological Medicine: A Journal of Research in Psychiatry and the Allied Sciences, 37, 961-970. doi:10.1017/S0033291706009706 
Ekman, P., \& Cordaro, D. (2011). What is meant by calling emotions basic. Emotion Review, 3, 364-370. doi:10.1177/1754073911410740

First, M., Spitzer, R., Gibbon, M., \& Williams, J. (1995). Structured Clinical Interview for Axis I DSM-IV Disorders - Patient Edition (SCIDI/P). New York: Biometrics Research Department, New York State Psychiatric Institute.

First, M., Spitzer, R., Gibbons, M., Williams, J., \& Benjamin, L. (1996). User's guide for the Structured Clinical Interview for DSM-IV Axis II Personality Disorders (SCID-II). New York: Biometrics Research Department, New York State Psychiatric Institute.

Fowles, D., Christie, M., Edelberg, R., Grings, W., Lykken, D., \& Venables, P. (1981). Publication recommendations for electrodermal measurements. Psychophysiology, 18, 232-239. doi: 10.1111/j.1469-8986.1981.tb03024.x

Garrard, C., Seidler, A., McKibben, A., McAlpine, L., \& Gordon, D. (1992). Spectral analysis of heart rate variability in bronchial asthma. Clinical Autonomic Research, 2, 105-111. doi:10.1007/BF018119665

Glaser, J. P., Van Os, J. J., Mengelers, R. R., \& Myin-Germeys, I. I. (2008). A momentary assessment study of the reputed emotional phenotype associated with borderline personality disorder. Psychological Medicine, 38, 1231-1239. doi:10.1017/S0033291707002322

Glenn, C. R., \& Klonsky, E. (2009). Emotion dysregulation as a core feature of borderline personality disorder. Journal of Personality Disorders, 23, 20-28. doi:10.1521/pedi.2009.23.1.20

Gratz, K. L., Tull, M. T., Reynolds, E. K., Bagge, C. L., Latzman, R. D., Daughters, S. B., \& Lejuez, C. W. (2009). Extending extant models of the pathogenesis of borderline 
personality disorder to childhood borderline personality symptoms: The roles of affective dysfunction, disinhibition, and self- and emotion-regulation deficits. Development and Psychopathology, 21, 1263-1291. doi:10.1017/S0954579409990150

Gratz, K. L., Rosenthal, M. Z., Tull, M. T., Lejuez, C. W., \& Gunderson, J. G. (2010). An experimental investigation of emotional reactivity and delayed emotional recovery in borderline personality disorder: The role of shame. Comprehensive Psychiatry, 51, 275285. doi:10.1016/j.comppsych.2009.08.005

Green, S. B. (1991). How many subjects does it take to do a regression analysis? Multivariate Behavioral Research, 26, 499-510. doi:10.1207/s15327906mbr2603_7

Gross, J. J., \& John, O. P. (2003). Individual differences in two emotion regulation processes: Implications for affect, relationships, and well-being. Journal of Personality and Social Psychology, 85, 348-362. doi:10.1037/0022-3514.85.2.348

Gross, J., \& Levenson, R. (1995). Emotion elicitation using films. Cognition and Emotion, 9, 87-108. doi:10.1080/02699939508408966

Gross, J. J., \& Thompson, R. A. (2007). Emotion regulation: Conceptual foundations. New York, NY, US: Guilford Press, New York, NY.

Haines, J., Williams, C. L., \& Brain, K. L. (1995). The psychopathology of incarcerated selfmutilators. The Canadian Journal of Psychiatry, 40, 514-522. Retrieved from http://www.ncbi.nlm.nih.gov/pubmed/8574986.

Hazlett, E. A., Zhang, J., New, A. S., Zelmanova, Y., Goldstein, K. E., Haznedar, M. M., . . . Chu, K. (2012). Potentiated amygdala response to repeated emotional pictures in borderline personality disorder. Biological Psychiatry, 72, 448-456. doi:10.1016/j.biopsych.2012.03.027 
Herpertz, S. C., Kunert, H. J., Schwenger, U. B., \& Sass, H. (1999). Affective responsiveness in borderline personality disorder: A psychophysiological approach. The American Journal of Psychiatry, 156, 1550-1556. Retrieved from http://www.ncbi.nlm.nih.gov/pubmed/10518165.

Herpertz, S. C., Schwenger, U. B., Kunert, H. J., Lukas, G., Gretzer, U., Nutzmann, J., ... Sass, H. (2000). Emotional responses in patients with borderline as compared with avoidant personality disorder. Journal of Personality Disorders, 14, 339-351. doi:10.1521/pedi.2000.14.4.339

Hertel, J., Schütz, A., \& Lammers, C. (2009). Emotional intelligence and mental disorder. Journal of Clinical Psychology, 65, 942-954. doi:10.1002/jclp.20597

Iverson, K. M., Follette, V. M., Pistorello, J., \& Fruzzetti, A. E. (2012). An investigation of experiential avoidance, emotion dysregulation, and distress tolerance in young adult outpatients with borderline personality disorder symptoms. Personality Disorders: Theory, Research, and Treatment, 3, 415-422. doi:10.1037/a0023703

Jacob, G. A., Arendt, J., Kolley, L., Scheel, C. N., Bader, K., Lieb, K., ... Tüscher, O. (2011). Comparison of different strategies to decrease negative affect and increase positive affect in women with borderline personality disorder. Behaviour Research and Therapy, 49, 6873. doi:10.1016/j.brat.2010.10.005

Jacob, G. A., Hellstern, K., Ower, N., Pillman, M., Scheel, C. N., Rüsch, N., ... Lieb, K. (2009). Emotional reactions to standardized stimuli in women with borderline personality disorder: Stronger negative affect, but no differences in reactivity. Journal of Nervous and Mental Disease, 197, 808-815. doi:10.1097/NMD.0b013e3181bea44d 
Jennings, J., Kamarck, T., Stewart, C., Eddy, M., \& Johnson, P. (1992). Alternate cardiovascular baseline assessment techniques: Vanilla or resting baseline. Psychophysiology, 29, 742750. Retrieved from http://www.ncbi.nlm.nih.gov/pubmed/1461961.

Johnson, P. A., Hurley, R. A., Benkelfat, C., Herpertz, S. C., \& Taber, K. H. (2003).

Understanding emotion regulation in borderline personality disorder: Contributions of neuroimaging. The Journal of Neuropsychiatry and Clinical Neurosciences, 15, 397-402. doi:10.1176/appi.neuropsych.15.4.397

Jovev, M., Chanen, A., Green, M., Cotton, S., Proffitt, T., Coltheart, M., \& Jackson, H. (2011). Emotional sensitivity in youth with borderline personality pathology. Psychiatry Research, 187, 234-240. doi:10.1016/j.psychres.2010.12.019

Koenigsberg, H. W., Harvey, P. D., Mitropoulou, V., Schmeidler, J., New, A. S., Goodman, M., .. . Siever, L. J. (2002). Characterizing affective instability in borderline personality disorder. The American Journal of Psychiatry, 159, 784-788.

doi:10.1176/appi.ajp.159.5.784

Kraemer, H. C., \& Blasey, C. M. (2004). Centring in regression analyses: A strategy to prevent errors in statistical inference. International Journal of Methods in Psychiatric Research, 13, 141-151. doi:10.1002/mpr.170

Kring, A. M., \& Gordon, A. H. (1998). Sex differences in emotion: Expression, experience, and physiology. Journal of Personality and Social Psychology, 74, 686-703. doi:10.1037/0022-3514.74.3.686

Kuo, J. R., \& Linehan, M. M. (2009). Disentangling emotion processes in borderline personality disorder: Physiological and self-reported assessment of biological vulnerability, baseline 
intensity, and reactivity to emotionally evocative stimuli. Journal of Abnormal Psychology, 118, 531-544. doi:10.1037/a0016392

Lang, P. J., Davis, M., \& Öhman, A. (2000). Fear and anxiety: Animal models and human cognitive psychophysiology. Journal of Affective Disorders, 61, 137-159. doi:10.1016/S0165-0327(00)00343-8

Leible, T. L., \& Snell, W. r. (2004). Borderline personality disorder and multiple aspects of emotional intelligence. Personality and Individual Differences, 37, 393-404. doi:10.1016/j.paid.2003.09.011

Licht, C. M., de Geus, E. C., van Dyck, R., \& Penninx, B. H. (2010). Longitudinal evidence for unfavorable effects of antidepressants on heart rate variability. Biological Psychiatry, 68, 861-868. doi:10.1016/j.biopsych.2010.06.032

Limberg, A., Barnow, S., Freyberger, H. J., \& Hamm, A. O. (2011). Emotional vulnerability in borderline personality disorder is cue specific and modulated by traumatization. Biological Psychiatry, 69, 574-582. doi:10.1016/j.biopsych.2010.10.024

Linehan, M. (1982). Demographic data schedule (DDS). Unpublished manuscript, University of Washington.

Linehan, M. M. (1993). Cognitive-behavioral treatment of borderline personality disorder. New York, NY, US: Guilford Press.

Littell R. C., Milliken G. A., Stroup W. W., \& Wofinger R. D. (1996). SAS system for mixed models. Cary, NC: SAS Institute Inc.

Lobbestael, J., \& Arntz, A. (2010). Emotional, cognitive and physiological correlates of abuserelated stress in borderline and antisocial personality disorder. Behaviour Research and Therapy, 48, 116-124. doi:10.1016/j.brat.2009.09.015 
Lobbestael J., Leurgans M., \& Arntz A. (2010). Inter-rater reliability of the Structured Clinical Interview for DSM-IV Axis I Disorders (SCID I) and Axis II Disorders (SCID II). Clinical Psychology and Psychotherapy, 18, 75-79. doi:10.1002/cpp.693

Lovell, D. (Producer), \& Zeffirelli, F. (Director). (1979). The champ [Motion picture]. United States: MGM/Path Home Video.

Ludäscher, P., Valerius, G., Stiglmayr, C., Mauchnik, J., Lanius, R. A., Bohus, M., \& Schmahl, C. (2010). Pain sensitivity and neural processing during dissociative states in patients with borderline personality disorder with and without comorbid posttraumatic stress disorder: A pilot study. Journal of Psychiatry and Neuroscience, 35, 177-184. Retrieved from http://www.ncbi.nlm.nih.gov/pubmed/20420768.

Lynch, T. R., Rosenthal, M. Z., Kosson, D. S., Cheavens, J. S., Lejuez, C. W., \& Blair, R. J. R. (2006). Heightened sensitivity to facial expressions of emotion in borderline personality disorder. Emotion, 6, 647-655. doi:10.1037/1528-3542.6.4.647

Maffei C., Fossati A., Agostoni I., Barraco, A., Bagnato, M., Deborah, D., ... Petrachi, M. (1997). Interrater reliability and internal consistency of the structured clinical interview for DSM-IV axis II personality disorders (SCID-II), version 2.0. Journal of Personality Disorders, 11, 279-284. doi:10.1521/pedi.1997.11.3.279

Marissen, M. A. E., Meuleman, L., \& Franken, I. H. A. (2010). Altered emotional information processing in borderline personality disorder: An electrophysiological study. Psychiatry Research, 181, 226-232. doi:10.1016/j.pscychresns.2009.10.006

McCormack, H. M., Horne, D. J., \& Sheather, S. (1988). Clinical applications of visual analogue scales: A critical review. Psychological Medicine: A Journal of Research in Psychiatry and the Allied Sciences, 18, 1007-1019. doi:10.1017/S0033291700009934 
Mindware Technologies LTD (2011a). Mindware heart rate variability (HRV) analysis user reference guide: Version 3.0.14. Unpublished manuscript. Gahanna, OH.

Mindware Technologies LTD (2011b). Mindware electrodermal activity (EDA) analysis user reference guide: Version 3.0.12. Unpublished manuscript. Gahanna, $\mathrm{OH}$.

Muehlenkamp, J. J., \& Gutierrez, P. M. (2004). An investigation of differences between selfinjurious behavior and suicide attempts in a sample of adolescents. Suicide and LifeThreatening Behavior, 34, 12-23. doi:10.1521/suli.34.1.12.27769

Menard, S. (1995). Applied logistic regression analysis. Sage university paper series on quantitative applications in the social sciences, 7-106. Thousand Oaks, CA: Sage.

Myers, R. (1990). Classical and modern regression with applications (2nd ed.). Boston, MA: Duxbury.

Niedtfeld, I., Kirsch, P., Schulze, L., Herpertz, S. C., Bohus, M., \& Schmahl, C. (2012). Functional connectivity of pain-mediated affect regulation in borderline personality disorder. Plos ONE, 7. doi:10.1371/journal.pone.0033293.

Niedtfeld, I., Schulze, L., Kirsch, P., Herpertz, S. C., Bohus, M., \& Schmahl, C. (2010). Affect regulation and pain in borderline personality disorder: A possible link to the understanding of self-injury. Biological Psychiatry, 68, 383-391. doi:10.1016/j.biopsych.2010.04.015

Niemela, M. J., Airaksinen, K. E. J., Huikuri, H. V. (1994). Effect of beta-blockers on heart rate variability in patients with coronary artery disease. Journal of the American College of Cardiology, 23, 1370-1377. doi:10.1016/0735-1097(94)90379-4

Nock, M. K., \& Kessler, R. C. (2006). Prevalence of and risk factors for suicide attempts versus suicide gestures: Analysis of the National Comorbidity Survey. Journal of Abnormal 
Psychology, 115, 616-623. doi:10.1037/0021-843X.115.3.616

Patterson, H. D. \& Thompson, R. (1971). Recovery of inter-block information when block sizes are unequal. Biometrika, 58, 545. Retrieved from http://www.lce.esalq.usp.br/arquivos/aulas/2012/LCE5872/Patterson.Thompson.71.pdf.

Paris, J., \& Zweig-Frank, H. (2001). The 27-year follow-up of patients with borderline personality disorder. Comprehensive Psychiatry, 42, 482-487.

doi:10.1053/comp.2001.26271

Pitman, R. K., Orr, S. P., Forgue, D. F., de Jong, J. B., \& Claiborn J. M. (1987).

Psychophysiologic assessment of posttraumatic stress disorder imagery in Vietnam combat veterans. Archives of General Psychiatry, 44, 970-975.

doi:10.1001/archpsyc.1987.01800230050009

Porges, S. W. (1997). Emotion: An evolutionary by-product of the neural regulation of the autonomic nervous system. (pp. 62-77). New York, NY, US: New York Academy of Sciences, New York, NY.

Porges, S. W. (2009). Reciprocal influences between body and brain in the perception and expression of affect: A polyvagal perspective. (pp. 27-54). New York, NY, US: W W Norton and Co, New York, NY.

Porges, S. W., Doussard-Roosevelt, J. A., \& Maita, A. K. (1994). Vagal tone and the physiological regulation of emotion. Monographs of the Society for Research in Child Development, 59, 167-186, 250-283. doi:10.2307/1166144

Rainville, P., Bechara, A., Naqvi, N., \& Damasio, A. R. (2006). Basic emotions are associated with distinct patterns of cardiorespiratory activity. International Journal of Psychophysiology, 61, 5-18. doi:10.1016/j.ijpsycho.2005.10.024 
Reitz, S., Krause-Utz, A., Pogatzki-Zahn, E., Ebner-Priemer, U., Bonus, M., \& Schmahl, C. (2012). Stress regulation and incision in borderline personality disorder-A pilot study modeling cutting behavior. Journal of Personality Disorders, 26, 605-615. doi:10.1521/pedi.2012.26.4.605

Ross, C. A. (2007) Borderline personality disorder and dissociation. Journal of Trauma and Dissociation, 8, 71-80. doi:10.1300/J229v08n01_05

Sadikaj, G., Russell, J. J., Moskowitz, D. S., \& Paris, J. (2010). Affect dysregulation in individuals with borderline personality disorder: Persistence and interpersonal triggers. Journal of Personality Assessment, 92, 490-500. doi:10.1080/00223891.2010.513287

Salsman, N. L., \& Linehan, M. M. (2012). An investigation of the relationships among negative affect, difficulties in emotion regulation, and features of borderline personality disorder. Journal of Psychopathology and Behavioral Assessment, 34, 260-267. doi:10.1007/s 10862-012-9275-8

Sansone, R. A., Chu, J. W., Wiederman, M. W., \& Lam, C. C. (2011). Eating disorder symptoms and borderline personality symptomatology. Eating and Weight Disorders, 16, e81-e85. Retrieved from http://www.ncbi.nlm.nih.gov/pubmed/21989102.

Sansone, R. A., McLean, J. S., \& Wiederman, M. W. (2008). The prediction of healthcare utilization by three self-report measures for borderline personality. International Journal of Psychiatry in Clinical Practice, 12, 312-315. doi:10.1080/13651500802238901

Sansone, R. A., \& Sansone, L. A. (2011). Substance use disorders and borderline personality: Common bedfellows. Innovations in Clinical Neuroscience, 8, 10-13. Retrieved from http://www.ncbi.nlm.nih.gov/pubmed/22010059. 
Saxon, E., Utt, K., Bozman, R. (Producers), \& Demme, J. (Director). (1991). Silence of the lambs [Motion picture]. United States: Orion Pictures.

Schmahl, C. G., Elzinga, B. M., Ebner, U. W., Simms, T., Sanislow, C., Vermetten, E., ... Bremner, J. D. (2004). Psychophysiological reactivity to traumatic and abandonment scripts in borderline personality and posttraumatic stress disorders: A preliminary report. Psychiatry Research, 126, 33-42. doi:10.1016/j.psychres.2004.01.005

Schulze, L., Domes, G., Krüger, A., Berger, C., Fleischer, M., Prehn, K., ... Herpertz, S. C. (2011). Neuronal correlates of cognitive reappraisal in borderline patients with affective instability. Biological Psychiatry, 69, 564-573. doi:10.1016/j.biopsych.2010.10.025

Scott, L. N., Levy, K. N., \& Granger, D. A. (2012). Biobehavioral reactivity to social evaluative stress in women with borderline personality disorder. Personality Disorders: Theory, Research, and Treatment, 4, 91-100. doi:10.1037/a0030117

Selby, E. A., \& Joiner, T. R (2009). Cascades of emotion: The emergence of borderline personality disorder from emotional and behavioral dysregulation. Review of General Psychology, 13, 219-229. doi:10.1037/a0015687

Welch, C., Linehan, M. M., Sylvers, P., Chittams, J., \& Rizvi, S. L. (2008). Emotional responses to self-injury imagery among adults with borderline personality disorder. Journal of Consulting and Clinical Psychology, 76, 45-51. doi:10.1037/0022-006X.76.1.45

Shea, M. T., Edelen, M. O., Pinto, A., Yen, S., Gunderson, J. G., Skodol, A. E., . . Morey, L. C. (2009). Improvement in borderline personality disorder in relationship to age. Acta Psychiatrica Scandinavica, 119, 143-148. doi:http://dx.doi.org/10.1111/j.16000447.2008.01274.x

Sheppes, G., \& Gross, J. J. (2011). Is timing everything? Temporal considerations in emotion 
regulation. Personality and Social Psychology Review, 15, 319-331.

doi: $10.1177 / 1088868310395778$

Singer, J. D., \& Willett, J. B. (2003). Applied longitudinal data analysis: Modeling change and event occurrence. New York, NY US: Oxford University Press.

Staebler, K., Gebhard, R., Barnett, W., \& Renneberg, B. (2009). Emotional responses in borderline personality disorder and depression: Assessment during an acute crisis and 8 months later. Journal of Behavior Therapy and Experimental Psychiatry, 40, 85-97. doi:10.1016/j.jbtep.2008.04.003

Stiglmayr, C. E., Shapiro, D. A., Stieglitz, R. D., Limberger, M. F., \& Bohus, M. (2001). Experience of aversive tension and dissociation in female patients with borderline personality disorder: A controlled study. Journal of Psychiatric Research, 35, 111-118. doi:10.1016/S0022-3956(01)00012-7

Soloff, P. H., Lynch, K. G., \& Kelly, T. M. (2002). Childhood abuse as a risk factor for suicidal behavior in borderline personality disorder. Journal of Personality Disorders, 16, 201214. doi:10.1521/pedi.16.3.201.22542

Tadić, A., Wagner, S., Hoch, J., Başkaya, Ö., von Cube, R., Skaletz, C.,... Dahmen, N. (2009). Gender differences in axis I and axis II comorbidity in patients with borderline personality disorder. Psychopathology, 42, 257-263. doi:10.1159/000224149

Thomsen, D. (2006). The association between rumination and negative affect: A review. Cognition and Emotion, 20, 1216-1235. doi:10.1080/02699930500473533

Toichi, M., Sugiura, T., Murai, T., \& Sengoku, A. (1997). A new method of assessing cardiac function and its cmparison with spectral analysis and coefficients of variation of R-R interval. Journal of Autonomic Nervous System, 62, 79-84. doi: 10.1016/S0165- 


\section{$\underline{1838(96) 00112-9}$}

Tomson, T., \& Kenneback, G. (2007). Arrhythmia, heart rate variability, and antiepileptic drugs. Epilepsia, 38, S48-S51. doi:10.1111/j.1528-1157.1997.tb06128.x

Verbeke, G. \& Molenberghs, G. (2000). Linear Mixed Models for Longitudinal Data. Springer.

Webb, D., \& McMurran, M. (2008). Emotional intelligence, alexithymia and borderline personality disorder traits in young adults. Personality and Mental Health, 2, 265-273. doi: $10.1002 /$ pmh. 48

Weinberg, A., Klonsky, E. D., \& Hajcak, G. (2009). Autonomic impairment in borderline personality disorder: A laboratory investigation. Brain and Cognition, 71, 279-286. doi:10.1016/j.bandc.2009.07.014

Woltman, H., Feldstain, A., MacKay, J. C., \& Rocchi, M. (2012). An introduction to hierarchical linear modeling. Tutorial in Quantitative Methods for Psychology, 8, 52-69. Retrieved from http://www.tqmp.org/Content/vol08-1/p052/p052.pdf.

Yeragani, V. K., Pohl, R., Balon, R., and Ramesh, C. C. (1992). Effect of imipramine treatment on heart rate variability measures. Neuropsychobiology, 26, 27-32. doi:10.1159/000069860

Zanarini, M. C., \& Frankenburg, F. R. (1997). Pathways to the development of borderline personality disorder. Journal of Personality Disorders, 11, 93-104. doi:10.1521/pedi.1997.11.1.93

Zanarini, M. C., Frankenburg, F. R., Dubo, E. D., Sickel, A. E., Trikha, A., Levin, A., \& Reynolds, V. (1998). Axis I comorbidity of borderline personality disorder. The American Journal of Psychiatry, 155, 1733-1739. Retrieved from http://www.ncbi.nlm.nih.gov/pubmed/9842784. 
Zanarini, M. C., Frankenburg, F. R., Reich, D. B., Fitzmaurice, G., Weinberg, I., \& Gunderson, J. G. (2008). The 10-year course of physically self-destructive acts reported by borderline patients and axis II comparison subjects. Acta Psychiatrica Scandinavica, 117, 177-184. doi:10.1111/j.1600-0447.2008.01155.x

Zanarini M.C., Skodol A.E., Bender D., Dolan, R., Sanislow, C., Schaefer, E., ... Gunderson, J. G. (2000). The Collaborative Longitudinal Personality Disorders Study: reliability of axis I and II diagnoses. Journal of Personality Disorders, 14, 291-299.

doi:10.1521/pedi.2000.14.4.291

Zanarini, M. C., Yong, L., Frankenburg, F. R., Hennen, J., Reich, D., Marino, M. F., \& Vujanovic, A. (2002). Severity of reported childhood sexual abuse and its relationship to severity of borderline psychopathology and psychosocial impairment among borderline inpatients. Journal of Nervous and Mental Disease, 190, 381-387.

doi:10.1097/00005053-200206000-00006 
Table 1

Participant Demographics by Group

\begin{tabular}{llll}
\hline Demographic & & Borderline Personality Disorder & Healthy Controls \\
\hline Ethnicity & & & \\
& Caucasian & $65 \%$ & $42.2 \%$ \\
& African American & $5 \%$ & $10.5 \%$ \\
& Asian American & $25 \%$ & $47.3 \%$ \\
Marital & Other & $5 \%$ & $0 \%$ \\
Status & & & \\
& & & \\
& Single & $84.2 \%$ & $84.2 \%$ \\
& Married & $10.5 \%$ & $10.5 \%$ \\
& Divorced & $5.3 \%$ & $5.3 \%$ \\
\hline
\end{tabular}


Table 2

Diagnostic Co-Morbidities in Percentages within the Borderline Personality Disorder Group

\begin{tabular}{lll}
\hline Diagnosis & Past & Current \\
\hline Anorexia nervosa & 10 & 0 \\
Bulimia nervosa & 10 & 5 \\
Binge eating & 0 & 0 \\
Major depressive disorder & 75 & 50 \\
Dysthymic disorder & & 5 \\
Depression not otherwise specified & 5 & 0 \\
Mood disorder (medically-induced) & 5 & 0 \\
Mood disorder (substance-induced) & 0 & 0 \\
Substance abuse or dependence & 50 & 10 (abuse only) \\
Posttraumatic stress disorder & 35 & 20 \\
Generalized anxiety disorder & & 5 \\
Obsessive-compulsive disorder & 15 & 10 \\
Specific phobia & 10 & 10 \\
Social anxiety general & 30 & 30 \\
Social anxiety eating & 5 & 5 \\
Panic disorder with agoraphobia & 0 & 0 \\
Panic disorder without agoraphobia & 25 & 15 \\
Anxiety not otherwise specified & & 0 \\
\hline
\end{tabular}


Table 3

Means, Standard Deviations, and Medians for Self-Reported Fear, Anger, and Sadness by Induction Type and Group

\begin{tabular}{|c|c|c|c|c|c|}
\hline Condition & Group & Variable & Mean & Median & Standard Deviation \\
\hline \multirow[t]{8}{*}{ Fear } & \multirow[t]{4}{*}{ BPD } & Self-reported fear (after induction) & 42.15 & 44.50 & 29.52 \\
\hline & & Self-reported fear (after washout period) & 26.46 & 10.00 & 29.53 \\
\hline & & Urges to engage in NSSI & 13.25 & 3.00 & 21.56 \\
\hline & & Urges to commit suicide & 14.15 & 3.00 & 22.13 \\
\hline & \multirow[t]{4}{*}{$\mathrm{HC}$} & Self-reported fear (after induction) & 28.70 & 20.00 & 25.42 \\
\hline & & Self-reported fear (after washout period) & 2.93 & 0 & 10.27 \\
\hline & & Urges to engage in NSSI & .25 & 0 & 1.12 \\
\hline & & Urges to commit suicide & .35 & 0 & 1.18 \\
\hline \multirow[t]{8}{*}{ Anger } & \multirow{4}{*}{ BPD } & Self-reported anger (after induction) & 39.20 & 40.00 & 25.83 \\
\hline & & Self-reported anger (after washout period) & 25.22 & 20.50 & 24.96 \\
\hline & & Urges to engage in NSSI & 13.15 & 3.50 & 20.22 \\
\hline & & Urges to commit suicide & 14.85 & 2.50 & 24.41 \\
\hline & \multirow[t]{4}{*}{$\mathrm{HC}$} & Self-reported anger (after induction) & 24.25 & 15.00 & 24.84 \\
\hline & & Self-reported anger (after washout period) & 3.47 & 0 & 7.84 \\
\hline & & Urges to engage in NSSI & .25 & 0 & 1.12 \\
\hline & & Urges to commit suicide & .25 & 0 & 1.12 \\
\hline \multirow[t]{8}{*}{ Sadness } & \multirow[t]{4}{*}{ BPD } & Self-reported sadness (after induction) & 49.25 & 50.50 & 21.59 \\
\hline & & Self-reported sadness (after washout recovery period) & 41.56 & 50.00 & 21.33 \\
\hline & & Urges to engage in NSSI & 13.15 & 3.50 & 20.22 \\
\hline & & Urges to commit suicide & 14.85 & 2.50 & 24.41 \\
\hline & \multirow[t]{4}{*}{$\mathrm{HC}$} & Self-reported sadness (after induction) & 35.05 & 30.00 & 22.87 \\
\hline & & Self-reported sadness (after washout recovery period) & 19.13 & 15.00 & 15.59 \\
\hline & & Urges to engage in NSSI & .25 & 0 & 1.12 \\
\hline & & Urges to commit suicide & .25 & 0 & 1.12 \\
\hline
\end{tabular}

Note. BPD = Borderline Personality Disorder group, $\mathrm{HC}=$ Healthy Control group, NSSI = non-suicidal self-injury. 
Table 4

Means and Standard Deviations for Psychophysiological Data Across Experiment Periods by Induction Type and Group

\begin{tabular}{|c|c|c|c|c|c|}
\hline Induction Type & Group & Variable & Before induction & During induction & Washout period \\
\hline \multicolumn{6}{|l|}{ Fear } \\
\hline & BPD & RSA & $5.71(S D=1.32)$ & $5.21(S D=1.04)$ & $5.40(S D=.94)$ \\
\hline & & SCR & $1.05(S D=1.28)$ & $1.51(S D=1.27)$ & $1.04(S D=.84)$ \\
\hline & $\mathrm{HC}$ & RSA & $6.46(S D=1.47)$ & $6.64(S D=.95)$ & $6.54(S D=1.20)$ \\
\hline & & SCR & $.16(S D=.50)$ & $1.07(S D=1.15)$ & $.61(S D=.65)$ \\
\hline \multicolumn{6}{|l|}{ Anger } \\
\hline & BPD & RSA & $5.22(S D=1.49)$ & $5.44(S D=1.09)$ & $5.61(S D=1.00)$ \\
\hline & & SCR & $1.72(S D=1.67)$ & $1.06(S D=1.12)$ & $1.02(S D=.94)$ \\
\hline & $\mathrm{HC}$ & RSA & $6.41(S D=1.24)$ & $6.44(S D=.98)$ & $6.73(S D=1.29)$ \\
\hline & & SCR & $.53(S D=.84)$ & $.50(S D=.58)$ & $.45(S D=.61)$ \\
\hline \multicolumn{6}{|l|}{ Sadness } \\
\hline & $\mathrm{BPD}$ & RSA & $6.50(S D=1.14)$ & $5.92(S D=1.03)$ & $5.67(S D=.77)$ \\
\hline & & SCR & $1.21(S D=1.32)$ & $1.11(S D=1.47)$ & $1.13(S D=.94)$ \\
\hline & $\mathrm{HC}$ & RSA & $6.36(S D=1.15)$ & $6.41(S D=.86)$ & $6.46(S D=1.20)$ \\
\hline & & SCR & $.37(S D=.60)$ & $.83(S D=1.30)$ & $.63(S D=.68)$ \\
\hline
\end{tabular}

Note. Standard deviations are in brackets. The SCR variable is untransformed and has not been divided by the number of seconds per segment. $\mathrm{BPD}=$ borderline personality disorder, $\mathrm{HC}=$ healthy controls, $\mathrm{RSA}=$ respiratory sinus arrhythmia, $\mathrm{SCR}=$ skin conductance responses, $\mathrm{SD}=$ standard deviation. 
Table 5

Hierarchical Linear Modeling Fixed Effects by Induction Type

\begin{tabular}{|c|c|c|c|c|c|c|}
\hline $\begin{array}{l}\text { Emotion } \\
\text { Elicited }\end{array}$ & $\begin{array}{l}\text { Psychophysiological } \\
\text { Index }\end{array}$ & Predictor & $\begin{array}{l}\text { Numerator Degrees of } \\
\text { Freedom }\end{array}$ & $\begin{array}{l}\text { Denominator Degrees of } \\
\text { Freedom }\end{array}$ & F-Statistic & P-value \\
\hline \multicolumn{7}{|l|}{ Fear } \\
\hline & \multicolumn{6}{|l|}{ RSA } \\
\hline & & Intercept & 1 & 30.20 & 535.43 & .000 \\
\hline & & Group & 1 & 30.20 & 3.04 & .09 \\
\hline & & Time* & 1 & 26.94 & 10.01 & .004 \\
\hline & & Urge to engage in NSSI & 1 & 30.19 & .80 & .38 \\
\hline & & Urge to commit suicide & 1 & 30.15 & .41 & .53 \\
\hline & & Group X Time* & 1 & 26.91 & 5.02 & .03 \\
\hline & & Group X Time X Urge to engage in NSSI & 1 & 26.95 & .46 & .50 \\
\hline & & Group X Time X Urge to commit suicide & 2 & 22.97 & 1.36 & .28 \\
\hline & \multicolumn{6}{|c|}{ 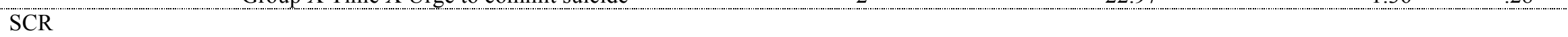 } \\
\hline & & Intercept & 1 & 41.31 & 35.73 & .000 \\
\hline & & Group & 1 & 41.31 & .01 & .91 \\
\hline & & Time & 1 & 39.53 & 2.90 & .10 \\
\hline & & Urge to engage in NSSI & 1 & 41.27 & .88 & .36 \\
\hline & & Urge to commit suicide & 1 & 41.15 & .31 & .58 \\
\hline & & Group X Time* & 1 & 39.44 & 8.71 & .005 \\
\hline & & Group X Time X Urge to engage in NSSI & 1 & 39.77 & 3.72 & .06 \\
\hline & & Group $X$ Time $X$ Urge to commit suicide & 2 & 27.25 & 3.29 & .05 \\
\hline \multicolumn{7}{|c|}{ 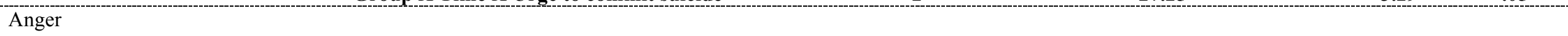 } \\
\hline & \multicolumn{6}{|l|}{ RSA } \\
\hline & & Intercept & 1 & 51.36 & 1537.41 & .000 \\
\hline & & Group* & $\mathbf{1}$ & 51.35 & 6.34 & .02 \\
\hline & & Time & 1 & 22.58 & .04 & .84 \\
\hline & & Urge to engage in NSSI & 1 & 50.83 & 2.39 & .13 \\
\hline & & Urge to commit suicide & 1 & 50.83 & 3.39 & .07 \\
\hline & & Group X Time & 1 & 22.58 & .06 & .81 \\
\hline & & Group $\mathrm{X}$ Time $\mathrm{X}$ Urge to engage in NSSI & 1 & 22.56 & .04 & .84 \\
\hline & & Group X Time X Urge to commit suicide & 1 & 22.56 & .03 & .87 \\
\hline & \multicolumn{6}{|c|}{ 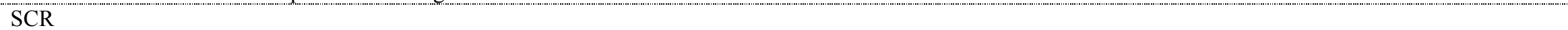 } \\
\hline & & Intercept & 1 & 46.11 & 35.76 & .000 \\
\hline & & Group* & 1 & 46.10 & 5.46 & .02 \\
\hline & & Time & 1 & 44.29 & 1.47 & .23 \\
\hline & & Urge to engage in NSSI & 1 & 45.72 & .34 & .56 \\
\hline
\end{tabular}


Urge to commit suicide

Group X Time

Group X Time X Urge to engage in NSSI

Group X Time X Urge to commit suicide

\begin{tabular}{ll} 
Sadness & \\
& Intercept \\
& Troup* \\
& Urge to engage in NSSI \\
& Urge to commit suicide \\
& Group X Time \\
& Group X Time X Urge to engage in NSSI \\
& Group X Time X Urge to commit suicide \\
& \\
& Intercept \\
& Group \\
& Time \\
& Urge to engage in NSSI \\
& Urge to commit suicide \\
& Group X Time \\
& Group X Time X Urge to engage in NSSI \\
& Group X Time X Urge to commit suicide \\
\hline
\end{tabular}

$\begin{array}{lll}45.72 & .48 & .49 \\ 43.95 & .18 & .68 \\ 43.10 & .01 & .92 \\ 43.13 & .01 & .94\end{array}$

43.13 .01

Note. $\mathrm{RSA}=$ respiratory sinus arrhythmia, $\mathrm{SCR}=$ skin conductance responses, NSSI = non-suicidal self-injury. Statistically significant effects are bolded with asterisks beside them. 
Table 6

Indications of Multicollinearity Between Predictors and Interaction Terms in Regression Analyses

\begin{tabular}{|c|c|c|c|c|c|c|c|}
\hline $\begin{array}{l}\text { Emotion } \\
\text { Elicited }\end{array}$ & & 1. & 2. & 3. & 4. & Tolerance & $\begin{array}{l}\text { Variance } \\
\text { Inflation Factor }\end{array}$ \\
\hline \multicolumn{8}{|l|}{ Fear } \\
\hline & 1. Urge to engage in NSSI & -- & & & & NA & NA \\
\hline & 2. Urge to commit suicide & $.83 * * *$ & -- & & & .07 & 14.93 \\
\hline & 3. Group X Urge to engage in NSSI & $1.00 * * *$ & $.82 * * *$ & -- & & NA & NA \\
\hline & 4. Group X Urge to commit suicide & $.76^{* * *}$ & $.81 * * *$ & $.76^{* * *}$ & -- & .12 & 8.32 \\
\hline \multicolumn{8}{|l|}{ Anger } \\
\hline & 1. Urge to engage in NSSI & -- & & & & NA & NA \\
\hline & 2. Urge to commit suicide & $.69 * * *$ & -- & & & .17 & 5.82 \\
\hline & 3. Group X Urge to engage in NSSI & $.99 * * *$ & $.66 * * *$ & -- & & NA & NA \\
\hline & 4. Group X Urge to commit suicide & $.52 * *$ & $.76^{* * *}$ & $.55 * * *$ & -- & .23 & 4.33 \\
\hline \multicolumn{8}{|l|}{ Sadness } \\
\hline & 1. Urge to engage in NSSI & -- & & & & .005 & 208.55 \\
\hline & 2. Urge to commit suicide & $.79 * * *$ & -- & & & .02 & 45.89 \\
\hline & 3. Group X Urge to engage in NSSI & $.96 * * *$ & $.71 * * *$ & -- & & .005 & 208.47 \\
\hline & 4. Group X Urge to commit suicide & $.48 * *$ & $.43 * *$ & $.57 * *$ & -- & .03 & 37.71 \\
\hline
\end{tabular}

Note. NSSI = non-suicidal self-injury. Tolerance and variance inflation factors denoted as "NA" are as such because these variables were so highly multicollinear that the model could not be run with both of them entered as predictors. $* * * p<.001, * * p<.01$ 
Table 7

Hierarchical Multiple Linear Regression Analyses of Self-Reported Changes in Emotional Intensity by Induction Type

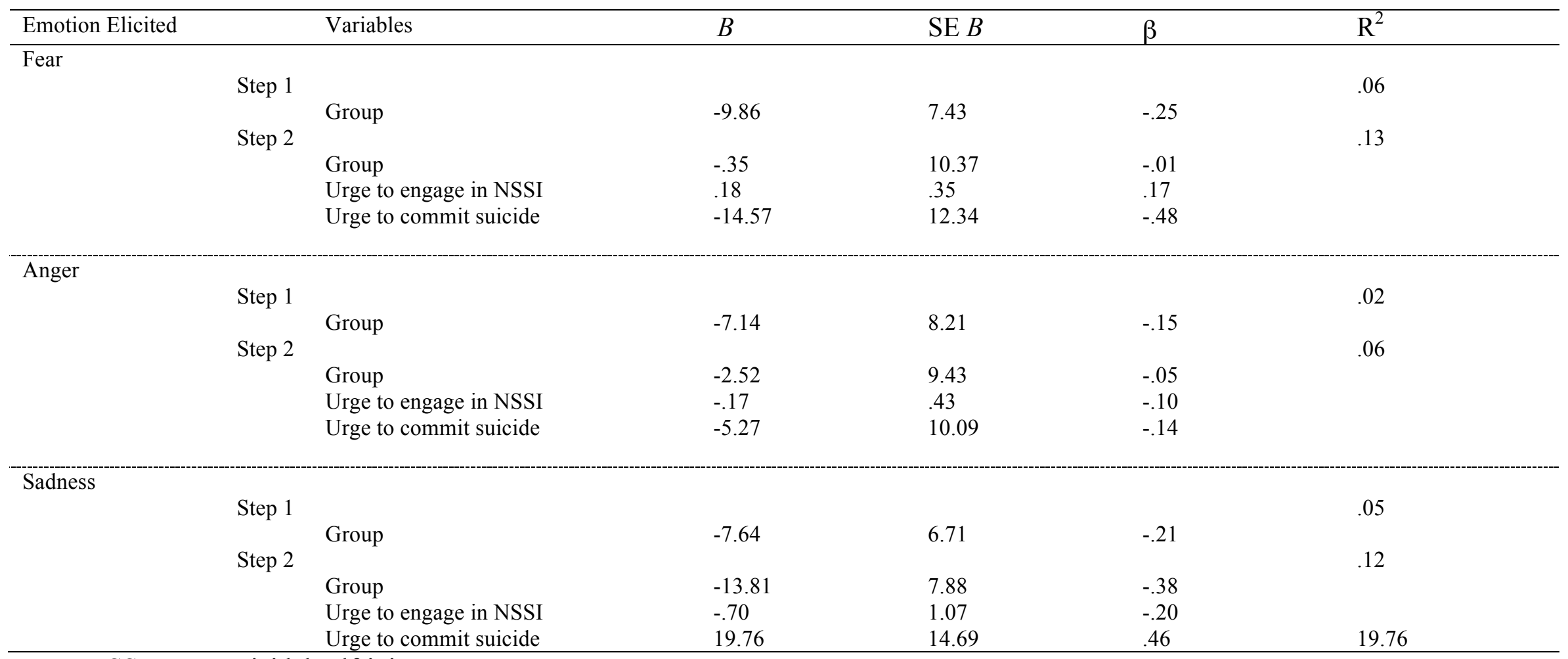

Note. NSSI $=$ non-suicidal self-injury. 


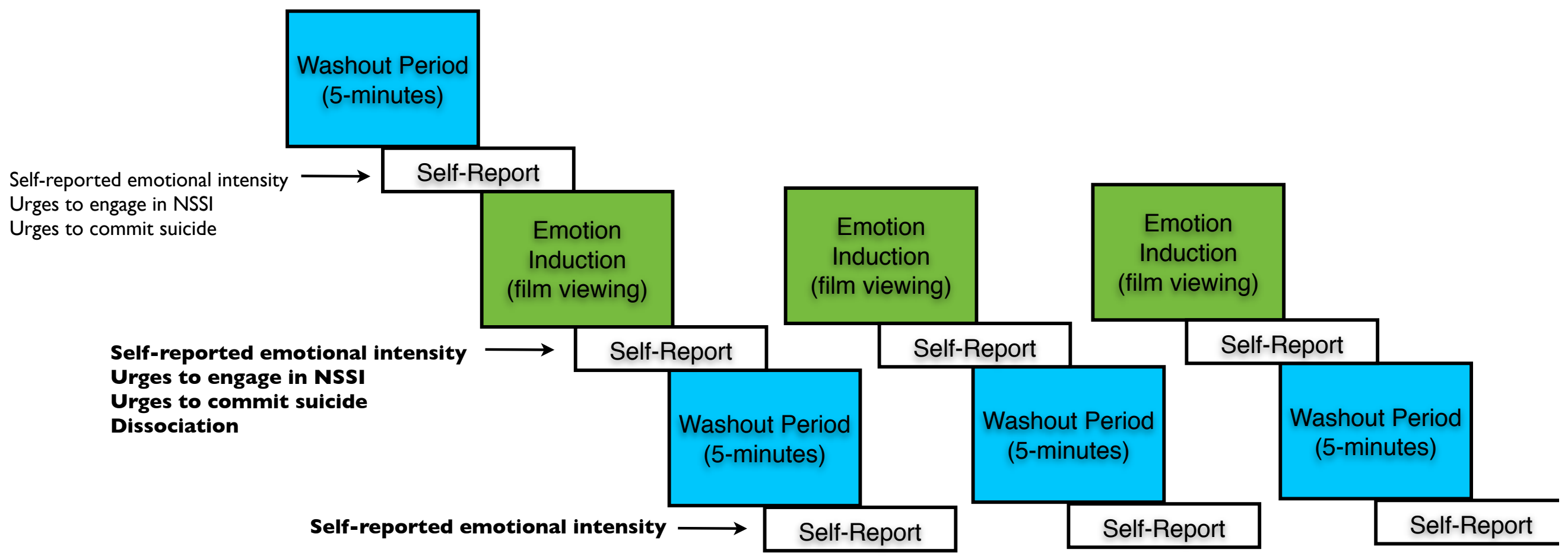

Figure 1. Schematic illustration of a sample participant's experimental trial. Self-report measures used in the present study are bolded. Film presentation order was counterbalanced across participants. 


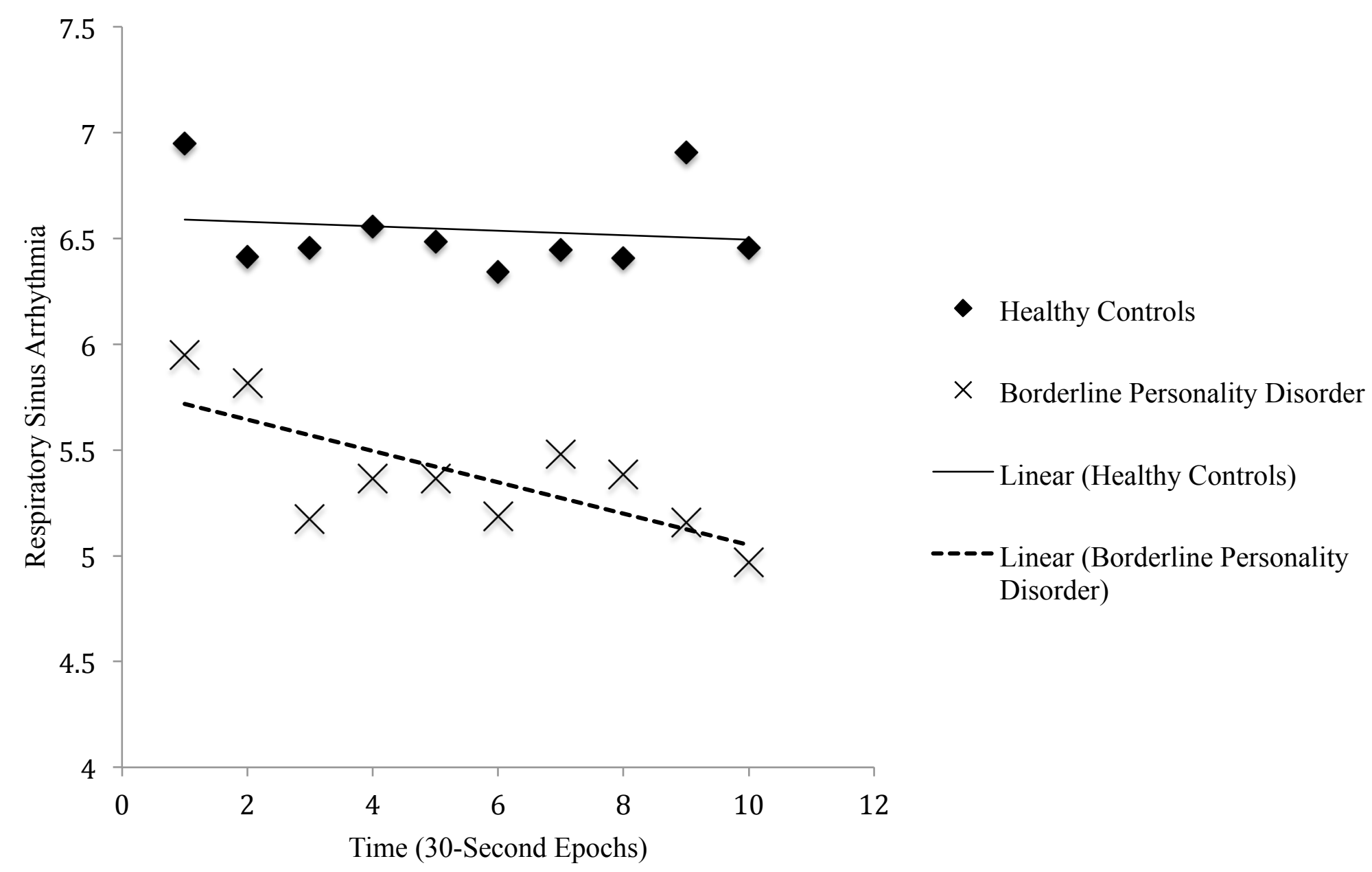

Figure 2. Group X time interaction in the fear condition predicting changes in respiratory sinus arrhythmia. 


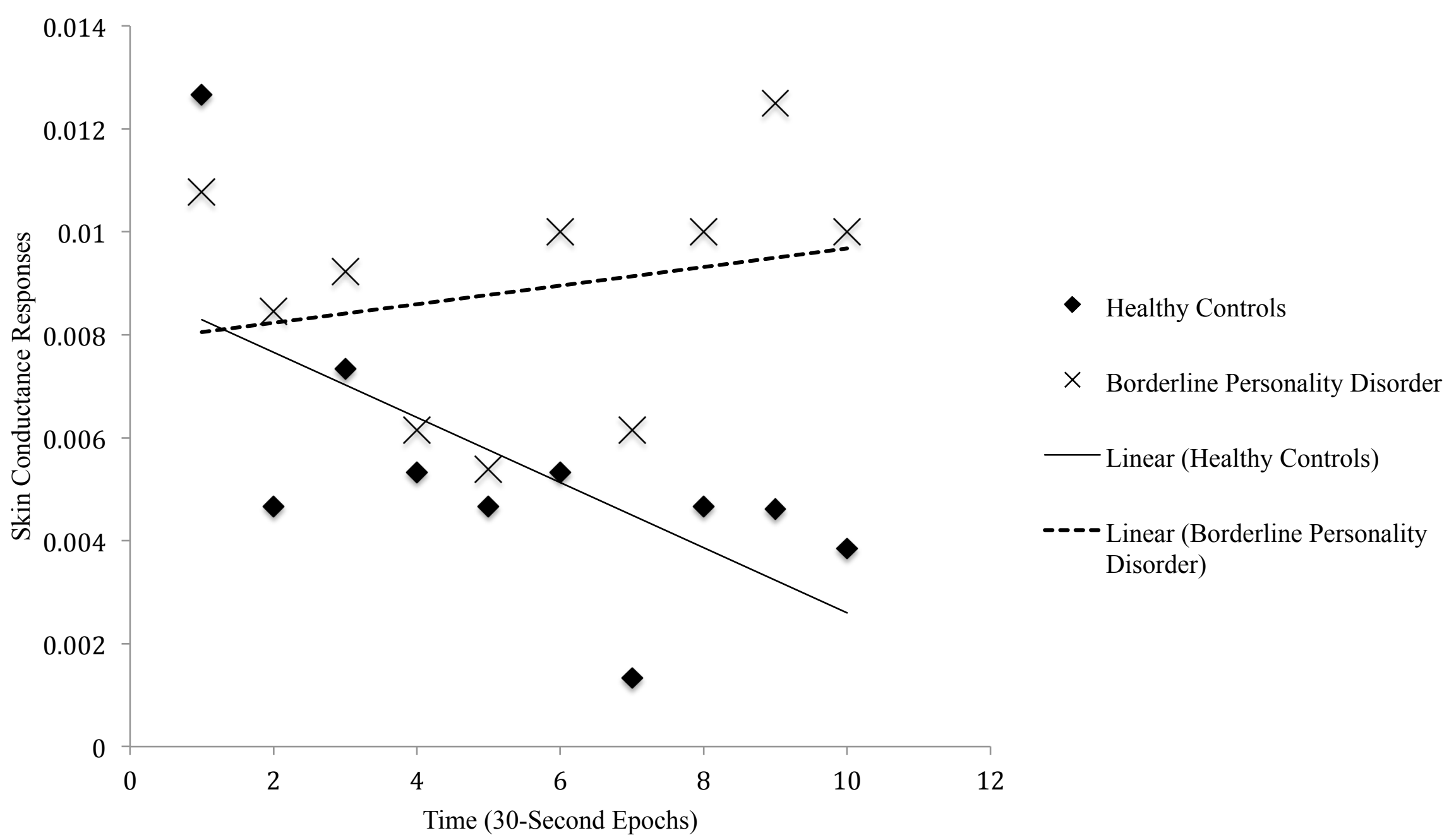

Figure 3. Group X time interaction in the fear condition predicting changes in skin conductance responses. 


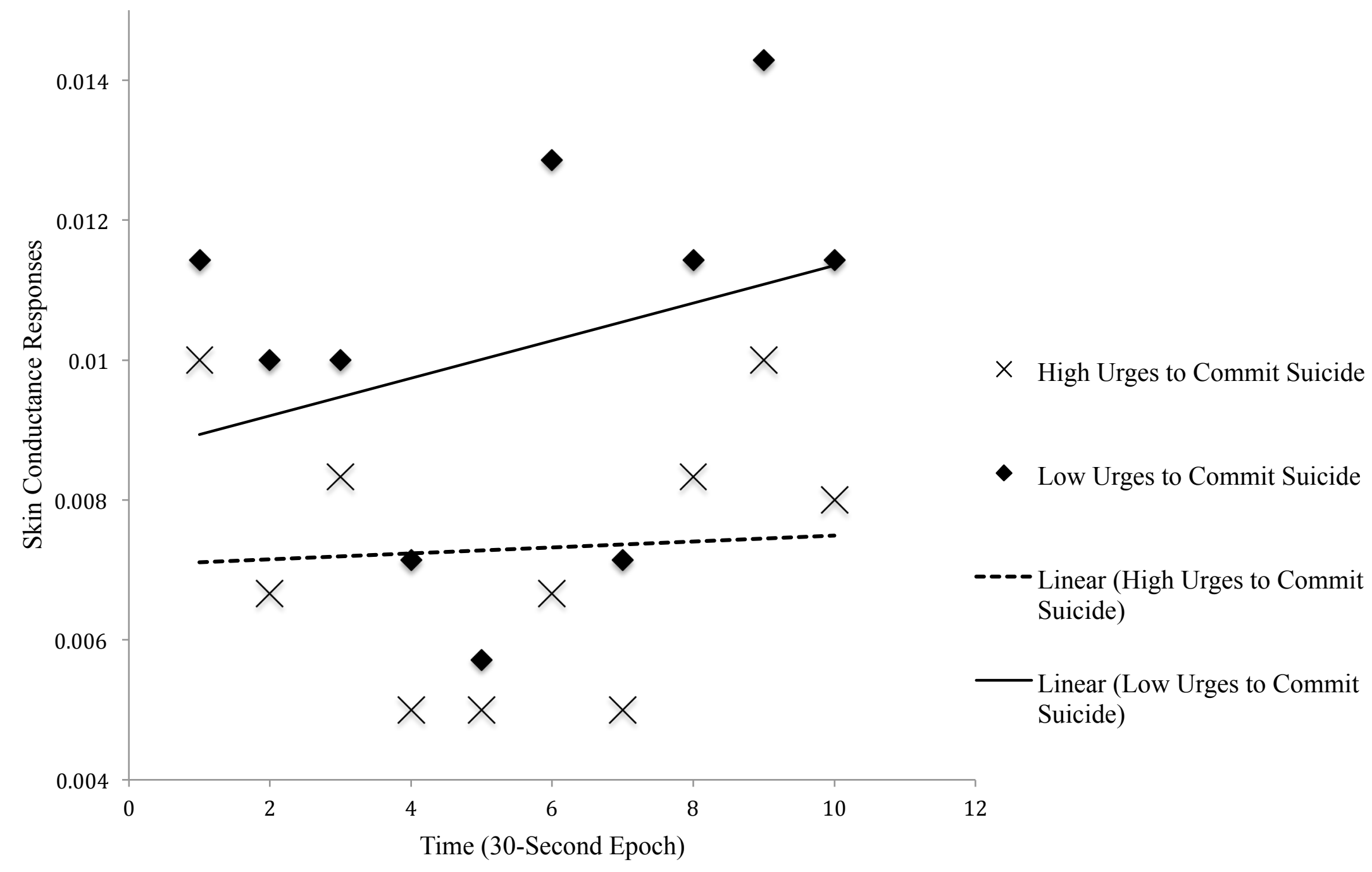

Figure 4. Changes in skin conductance responses over time grouped by high and low urges to commit suicide in the borderline personality disorder group only. High and low urges to commit suicide were delineated by a median split. 